Supporting Information

\title{
“Open" nonporous Nonasil zeolite structure for selective catalysis
}

Kun $\mathrm{Lu}^{\dagger, \S,+}$, Yaqi Fan ${ }^{\ddagger},+$ Ju Huang ${ }^{\ddagger}$, Jilong Wang ${ }^{\dagger}$, Hao Xu ${ }^{\dagger *}$, Jingang $\mathrm{Jiang}^{\dagger}$, Yanhang $\mathrm{Ma}^{\ddagger *}$, Peng $\mathrm{Wu}^{\dagger *}$

†Shanghai Key Laboratory of Green Chemistry and Chemical Processes, School of Chemistry and Molecular Engineering, East China Normal University, North Zhongshan Road 3663, Shanghai 200062, China Tel: +86-21-6223-2292

Fax: +86-21-6223-2292

E-mail address: hxu@chem.ecnu.edu.cn (H. Xu); pwu@chem.ecnu.edu.cn (P. Wu)

${ }^{\ddagger}$ School of Physical Science and Technology, ShanghaiTech University, Shanghai 201210, China

E-mail address: mayh2@shanghaitech.edu.cn (Y. Ma)

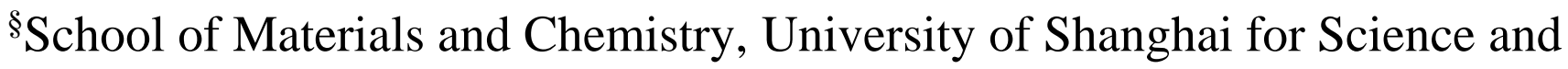
Technology, Shanghai 200082, China

+ These authors contributed equally to this work. 


\section{Table of Contents}

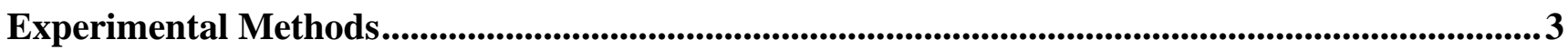

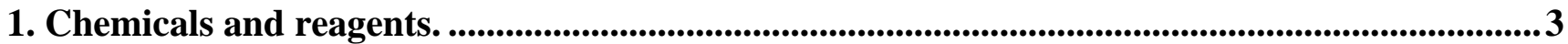

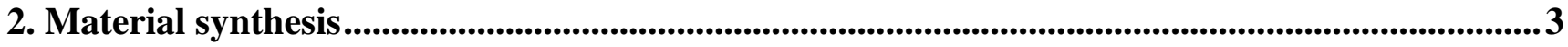

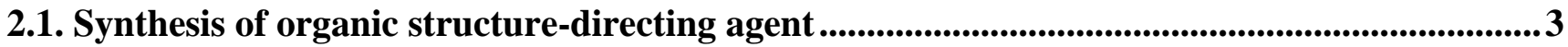

2.2 Synthesis of ECNU-27 and conventional NON zeolite ...........................................................4

2.3 Dealumination and ammonium cation-exchange procedures .............................................................4

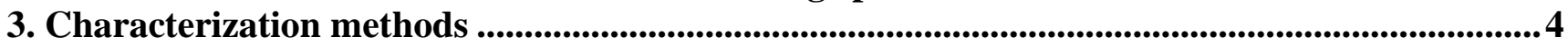

4. Catalytic reactions.............................................................................................................................................6 6

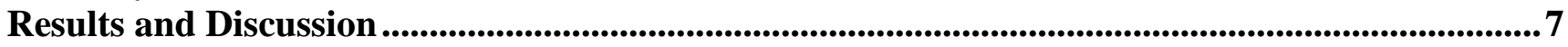

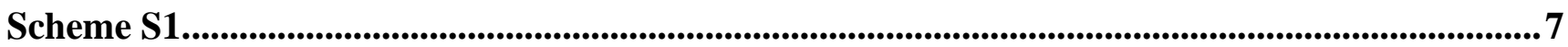

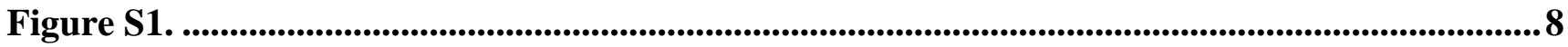

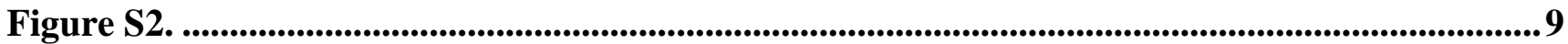

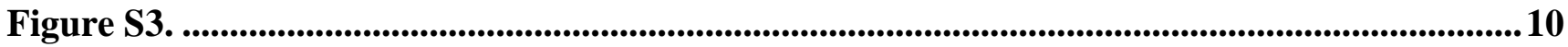

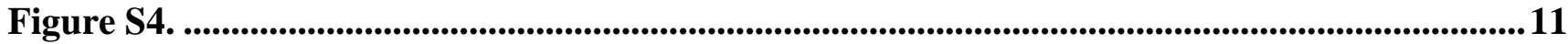

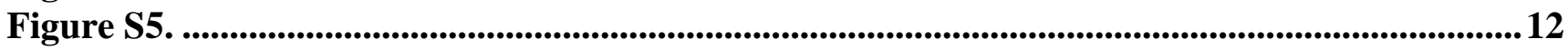

Figure S6. ........................................................................................................................................................................... 13

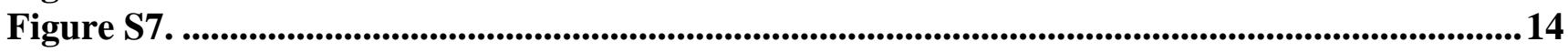

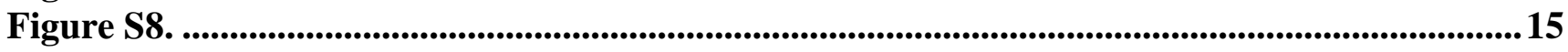

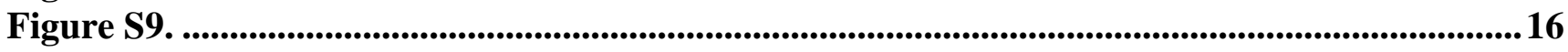

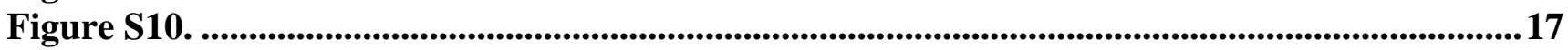

Figure S11. ................................................................................................................................................................. 18

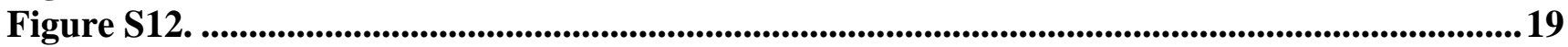

Figure S13. ....................................................................................................................................................20

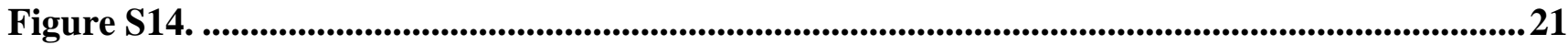

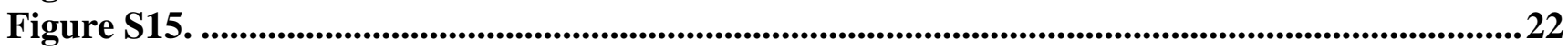

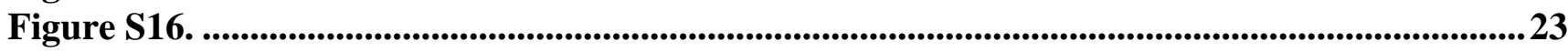

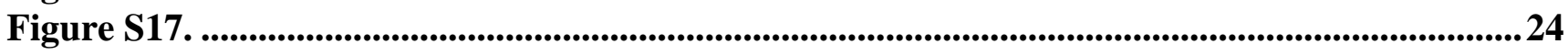

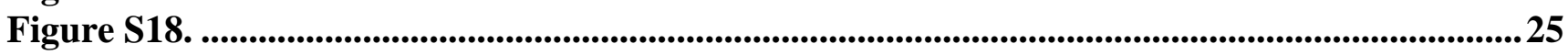

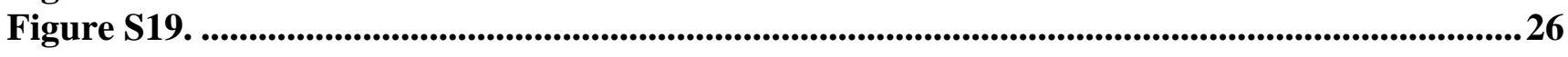

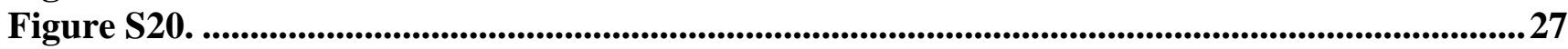

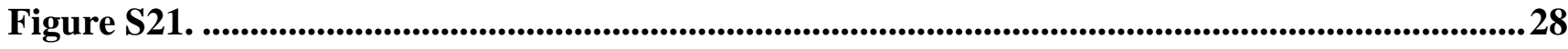

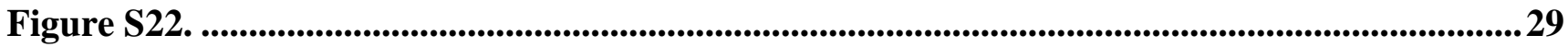

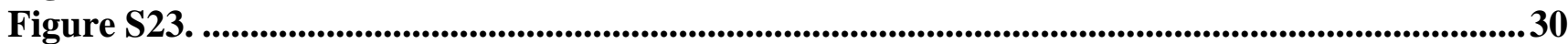

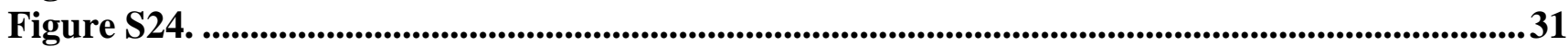

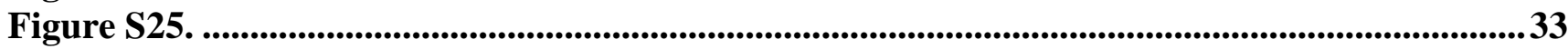

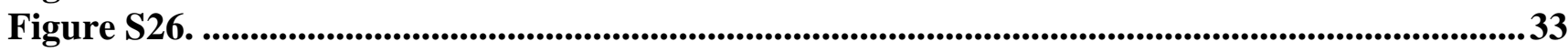

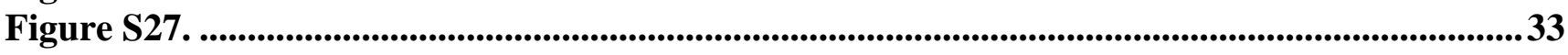

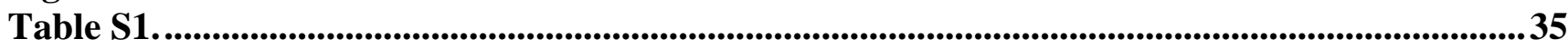

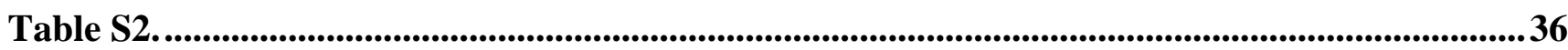

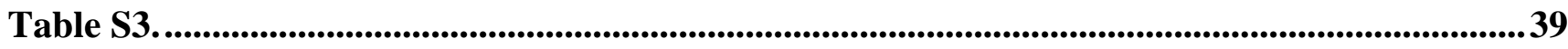

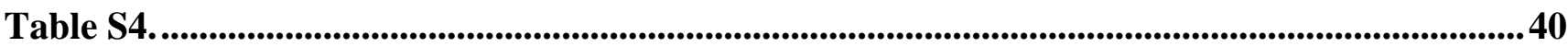

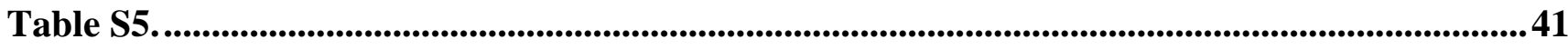

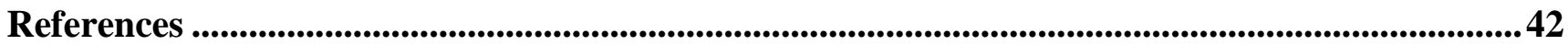




\section{Experimental Methods}

\section{Chemicals and reagents.}

All chemicals and reagents were obtained from commercial suppliers and used without further purification. Colloidal silica (30 wt.\%), sodium aluminate $\left(\mathrm{Na}_{2} \mathrm{O}, 40.4 \mathrm{wt} . \% ; \mathrm{Al}_{2} \mathrm{O}_{3}, 49.84 \mathrm{wt} . \%\right)$, acetonitrile, dichloromethane, diethyl ether, $N, N$-dimethylcyclohexylamine (> 99\%), $\mathrm{NaOH}(>99 \%)$, nitric acid (65.0\%), tetraethyl orthosilicate (TEOS) and 1,4dibromobutane (> 99\%) were purchased from Shanghai Sinopharm Chemical Reagent Co., Ltd. $N, N$ dimethylhexadecylamine (> 99\%) was purchased from TCI. The chemicals were used as received without further purification. ZSM-5 $(\mathrm{Si} / \mathrm{Al}=15)$ and MOR $(\mathrm{Si} / \mathrm{Al}=7.8)$ zeolites were purchased from Shangsi Fine Chemical Co., Ltd. Beta $(\mathrm{Si} / \mathrm{Al}=11)$ zeolite was purchased from Shanghai Xinnian Zeolite Co., Ltd. USY $(\mathrm{Si} / \mathrm{Al}=6.4)$ zeolite was purchased from Wenzhou Huahua Catalyst Co., Ltd. MCM-22 ( $\mathrm{Si} / \mathrm{Al}=12)$ was purchased from Nankai University Catalyst Co., Ltd.

\section{Material synthesis}

\subsection{Synthesis of organic structure-directing agent}

$\mathrm{C}_{16} \mathrm{H}_{33}-\mathrm{N}^{+}-\left(\mathrm{CH}_{3}\right)_{2}-\mathrm{C}_{4} \mathrm{H}_{8}-\mathrm{N}^{+}-\left(\mathrm{CH}_{3}\right)_{2}$-cyclohexylammonium (Che-4-16), used as the organic structure-directing agent (OSDA) for zeolite preparation, was chemically synthesized as follows. Firstly, 0.1 mol of $N, N$ dimethylcyclohexylamine and $1 \mathrm{~mol}$ of 1,4-dibromobutane were dissolved in $500 \mathrm{~mL}$ of acetonitrile and the resultant mixture was heated at $355 \mathrm{~K}$ for $16 \mathrm{~h}$ under stirring and refluxing. After cooling down to room temperature, the solvent was removed by rotary evaporation, and the solid product was recrystallized from dichloromethane and washed with diethyl ether. After the second rotary evaporation, the intermediate product $\left(\mathrm{Br}-\mathrm{C}_{4} \mathrm{H}_{8}-\mathrm{N}^{+}-\left(\mathrm{CH}_{3}\right)_{2^{-}}\right.$ cyclohexylammonium bromide) was obtained, named as $\mathrm{Che}-\mathrm{N}^{+}(\mathrm{Me})_{2}-4-\mathrm{Br}, \mathrm{Br}$.

Secondly, $10 \mathrm{~g}$ of Che- $\mathrm{N}^{+}(\mathrm{Me})_{2}-4-\mathrm{Br}, \mathrm{Br}^{-}$and a 3-fold molar excess of $\mathrm{N}, \mathrm{N}$-dimethylhexadecylamine were dissolved in $500 \mathrm{~mL}$ of acetonitrile, and refluxed at $355 \mathrm{~K}$ for $16 \mathrm{~h}$. The solution was cooled down and then the solvent was removed by rotary evaporation, and the product of Che-4-16(Br) $)_{2}$ was washed with diethyl ether. The molecular structure and phase purity of Che-4-16(Br) $)_{2}$ were verified by ${ }^{1} \mathrm{H}$ and ${ }^{13} \mathrm{C}$ NMR spectra (Figure S1 and Figure S2). Thirdly, the product was converted to hydroxide form using hydroxide exchange anion resin in water. After filtration, a part of water was removed by rotary evaporation to obtain desired concentration.

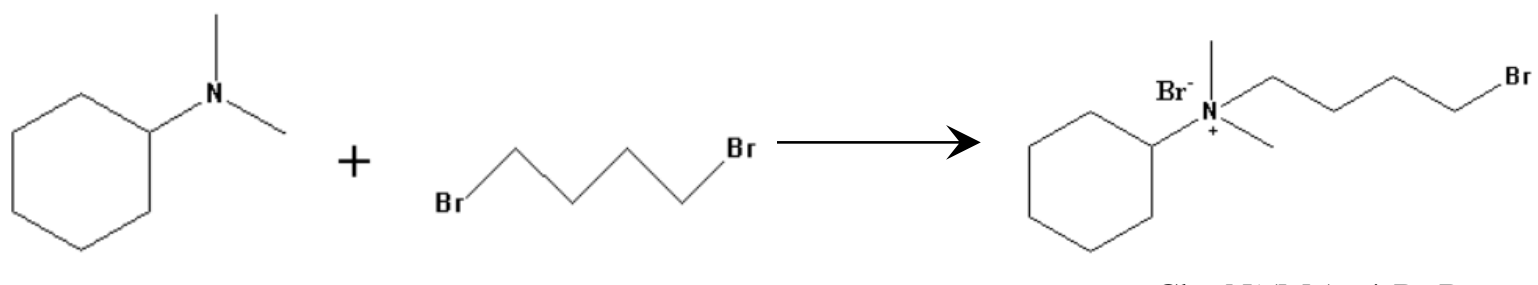

Che- $\mathrm{N}^{+}(\mathrm{Me})_{2}-4-\mathrm{Br}, \mathrm{Br}^{-}$ 


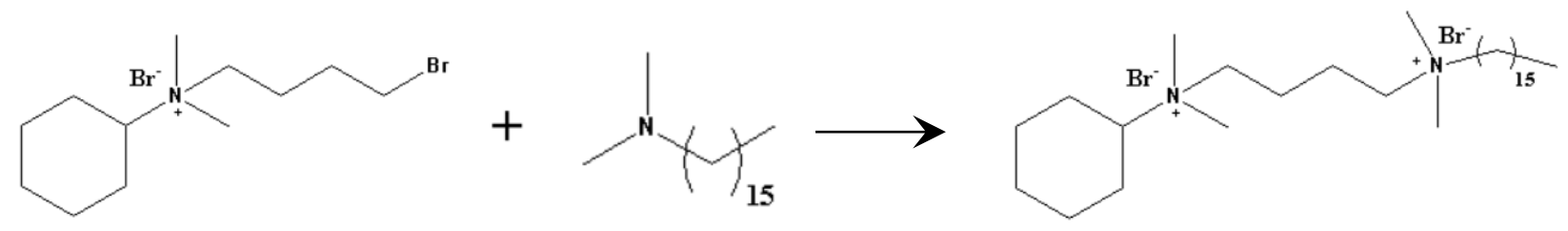

Che- $\mathrm{N}^{+}(\mathrm{Me})_{2}-4-\mathrm{Br}, \mathrm{Br}^{-}$

Che-4-16(Br) 2

\subsection{Synthesis of ECNU-27 and conventional NON zeolite}

ECNU-27 was hydrothermally synthesized with the hydroxide form Che-4-16 as OSDA. First of all, desired amounts of sodium hydroxide and sodium aluminate were dissolved in deionized water, and then the aqueous solution of Che4-16 was added dropwise into the above solution. The mixture was stirred for 15 min, and then colloidal silica was added. If necessary, evaporation was carried out to adjust the water amount, the procedure of which was facilitated by a stream of air while monitoring the gravimetrical change. The synthetic gel with a typical molar composition of 10 $\mathrm{Na}_{2} \mathrm{O}: 2.5 \mathrm{Al}_{2} \mathrm{O}_{3}: 100 \mathrm{SiO}_{2}: 10$ OSDA : $4000 \mathrm{H}_{2} \mathrm{O}$ was kept stirring for $1 \mathrm{~h}$ and then aged at $353 \mathrm{~K}$ for 1 day. Finally, the crystallization was carried out in $50 \mathrm{~mL}$ Teflon-line stainless-steel autoclaves under rotation (10 rpm) at $443 \mathrm{~K}$. The as-made solid product was collected by filtration, washed thoroughly with distilled water, dried at $353 \mathrm{~K}$ overnight, and denoted as ECNU-27-P (P means parent). The ECNU-27-P ( $\mathrm{Si} / \mathrm{Al}=28.1)$ sample was calcined in air by increasing the temperature from ambient temperature to $873 \mathrm{~K}$ at $100 \mathrm{~K} \mathrm{~h}^{-1}$ and holding the sample at $873 \mathrm{~K}$ for $6 \mathrm{~h}$.

For contrast experiment, a conventional NON zeolite was prepared following the procedure in the reference ${ }^{1}$. Tetramethylethylenediamine was employed as OSDA. The typical gel composition was $10 \mathrm{Na}_{2} \mathrm{O}: 2.5 \mathrm{Al}_{2} \mathrm{O}_{3}: 100$ $\mathrm{SiO}_{2}$ : 10 OSDA : $4000 \mathrm{H}_{2} \mathrm{O}$, and it was crystallized at $403 \mathrm{~K}$ for 4 days. After crystallization, the solids were collected by filtration, washed thoroughly with distilled water, and dried at $353 \mathrm{~K}$ overnight. The collected sample (Si/Al=36) was calcined in air at $873 \mathrm{~K}$ for $6 \mathrm{~h}$.

\subsection{Dealumination and ammonium cation-exchange procedures}

With the purpose to adjust the Si/Al ratio suitable for the reaction of 1-butene cracking, the acid treatment of ZSM-5, MOR, Beta and MCM-22 were carried out in $6 \mathrm{M} \mathrm{HNO}_{3}$ aqueous solution with a liquid-to-solid ratio of $50 \mathrm{~mL}: 1 \mathrm{~g}$ at $413 \mathrm{~K}$ for $24 \mathrm{~h}$. This process was repeated multiple times to reach the desired $\mathrm{Si} / \mathrm{Al}$ molar ratio. The calcined samples of USY, NON and ECNU-27 were ion-exchanged three times using $1 \mathrm{M} \mathrm{NH} 4 \mathrm{Cl}$ aqueous solution at $353 \mathrm{~K}$ for $2 \mathrm{~h}$, and collected by centrifugation, washed with distilled water, and finally calcined at $873 \mathrm{~K}$ for $6 \mathrm{~h}$ to produce protontype zeolites.

\section{Characterization methods}

ECNU-27 with the product $\mathrm{Si} / \mathrm{Al}$ ratio of 28.1 was selected for characterization (Table S1, No.3). The structure of the OSDA molecules was confirmed by liquid-phase ${ }^{1} \mathrm{H}$ NMR and ${ }^{13} \mathrm{C}$ NMR spectra, which were recorded on a BRUKER AV 500 instrument using deuterated water as solvent and tetramethylsilane (TMS) as internal standard. The powder 
$\mathrm{X}$-ray diffraction (PXRD) patterns were collected on a Rigaku Ultima IV X-ray diffractometer using $\mathrm{Cu}-\mathrm{K} \alpha$ radiation $(\lambda=1.5418 \AA)$ in a scanning range of $2 \theta=5^{\circ}-35^{\circ}$ to confirm the structure and crystallinity of the zeolite samples. The voltage and current were $35 \mathrm{kV}$ and $25 \mathrm{~mA}$, respectively. The high-resolution PXRD patterns were collected on a Bruker D8 Advance X-ray diffractometer using $\mathrm{Cu}-\mathrm{K} \alpha 1$ radiation $(\lambda=1.5406 \AA)$ in a scanning range of $2 \theta=5^{\circ}-35^{\circ}$. The UV-Raman spectra were collected with an excitation line at $244 \mathrm{~nm}$ and with a spectral resolution of $2 \mathrm{~cm}^{-1}$ on UV Raman spectrograph utilizing a Jobin-Yvon T6400 triple-stage spectrograph.

To determine the morphology and crystal sizes, scanning electron microscope (SEM) image were performed on a JEOL JSM-7800F prime at a low landing energy ( $1 \mathrm{KeV}$, in gentle-beam mode). TEM images and 3D-EDT data were obtained with a JEOL JEM-2100 Plus with an accelerating voltage of $200 \mathrm{KV}$ (Cs=1mm, point resolution $0.19 \AA)$. A TVIPS (XF416) CMOS camera was used for high signal to noise ratio EDT data acquisition. A single high tilt sample holder (Produced by JEOL, Model 21010) was used to collect EDT data at room temperature. The EDT data were automatically collected under the control of fast-EDT software. The collection parameters were finally optimized as spot size (3), exposure time (500 ms) with speed (1). In total, $250 \mathrm{ED}$ frames (tilt range from $-50^{\circ}$ to $53^{\circ}$ ) were recorded for the ECNU-27 sample. Using EDT-Process software, we processed all these data to obtain unit cell parameters as well as intensity information. The space group symmetry was analyzed based on observed reflection conditions. Finally, the structure was solved using SIR2019 software.

The $\mathrm{N}_{2}$ and Ar sorption isotherms were measured at $77 \mathrm{~K}$ and $87.3 \mathrm{~K}$ on a BELSORP-MAX and Micromeritics ASAP2020 adsorption instruments, respectively, after activating the samples at $573 \mathrm{~K}$ under vacuum for at least $5 \mathrm{~h}$. The calculation of specific surface area by Brunauer-Emmett-Teller (BET) method was carried out using the data in the relative pressure region of $p / p_{0}=0.05-0.25$.

The bulk Si/Al ratios were determined by ICP-AES on IRIS Intrepid II XSP after dissolving the zeolite powder in HF solution. The thermogravimetric and differential thermal analyses (TG-DTA) were performed on a METTLER TOLEDO TGA/DSC 3+ apparatus from $303 \mathrm{~K}$ to $1200 \mathrm{~K}$ at a heating rate of $10 \mathrm{~K} \mathrm{~min}^{-1}$ in air. The CHN chemical analysis was carried out on Elementar Vario EL III.

The solid-state ${ }^{13} \mathrm{C},{ }^{29} \mathrm{Si}$ and ${ }^{27} \mathrm{Al}$ MAS NMR spectra were obtained on a VARIAN VNMRS 400WB NMR spectrometer using single-pulse method at a frequency of 100.54, 79.43 and 104.18 MHz, respectively. ${ }^{13} \mathrm{C}$ MAS NMR spectra were recorded with a $7.5 \mathrm{~mm}$ T3HX probe at spinning rate of $5 \mathrm{kHz} .{ }^{29} \mathrm{Si}$ MAS NMR spectra were acquired with a $7.5 \mathrm{~mm}$ T3HX probe at spinning rate of $3 \mathrm{kHz}$, and a recycling delay of $60 \mathrm{~s} .{ }^{27} \mathrm{Al}$ MAS NMR spectra were recorded at spinning rate of $10.0 \mathrm{kHz}$, and a recycling delay of $4 \mathrm{~s}$. To investigate the interaction between organic and inorganic species in ECNU-27, the solid-state HETCOR NMR experiments were carried out on a Bruker Advance III spectrometer (9.4 T), equipped with triple resonance 4-mm MAS probes under a magic-angle-spinning speed of $6 \mathrm{kHz}$. The NMR resonance frequencies for ${ }^{1} \mathrm{H},{ }^{13} \mathrm{C}$, and ${ }^{29} \mathrm{Si}$ channels were set at 400.214, 100.613, and $79.495 \mathrm{MHz}$, respectively. The two-dimensional ${ }^{1} \mathrm{H}_{-}{ }^{13} \mathrm{C}$ and ${ }^{1} \mathrm{H}_{-}{ }^{29} \mathrm{Si} \mathrm{HETCOR} \mathrm{NMR} \mathrm{spectra} \mathrm{were} \mathrm{acquired} \mathrm{with} \mathrm{CP}$ contact time of $2000 \mu \mathrm{s}$ and $5000 \mu \mathrm{s}$ and a recycle delay was set for $0.5 \mathrm{~s}$ and $0.75 \mathrm{~s}$, respectively. 
The acid property was determined by temperature-programmed desorption of ammonia $\left(\mathrm{NH}_{3}-\mathrm{TPD}\right)$ with a Micrometrics AutoChem II Chemisorption Analyzer. Typically, $0.1 \mathrm{~g}$ of sample was pretreated in helium stream (25 $\mathrm{mL} \mathrm{min}{ }^{-1}$ ) at $873 \mathrm{~K}$ for $1 \mathrm{~h}$. The adsorption of $\mathrm{NH}_{3}$ was carried out at $323 \mathrm{~K}$ for $1 \mathrm{~h}$. The sample was flushed with helium at $373 \mathrm{~K}$ for $2 \mathrm{~h}$ to remove physisorbed $\mathrm{NH}_{3}$ from the catalyst surface. The TPD profiles were then recorded at a heating rate of $10 \mathrm{~K} \mathrm{~min}^{-1}$ from $303 \mathrm{~K}$ to $1200 \mathrm{~K}$. The Brønsted and Lewis acid sites of the samples were further characterized by pyridine-adsorbed IR spectra on a Nicolet iS50 FT-IR Spectrometer. The samples were activated at $773 \mathrm{~K}$ for $1 \mathrm{~h}$ under vacuum and then dosed with an excess of pure pyridine vapor, and then IR spectra were collected after the evacuation at required temperature for $1 \mathrm{~h}$ each. The FT-IR spectra in the hydroxyl stretching region were recorded by a Nicolet NEXUS 670 FT-IR spectrometer at a resolution of $2 \mathrm{~cm}^{-1}$ using the self-supported wafer, IR spectra were collected after the evacuation at $723 \mathrm{~K}$ for $1 \mathrm{~h}$.

\section{Catalytic reactions}

Catalytic cracking of 1-butene over the zeolite catalysts were carried out in a stainless steel continuous plug-flow reactor (i.d. $=8 \mathrm{~mm}$ ) with a thermocouple in the center of the catalyst bed. Pure 1-butene $(>99.5 \%)$ without dilution was used as the feed. The catalyst was activated at $823 \mathrm{~K}$ for 1 hour under a nitrogen flow before starting each reaction run. Then, 1-butene was passed through the reactor at desired temperatures. The reaction products were analyzed on an online Kechuang GC-9800 gas chromatograph equipped with FID detector and a $\mathrm{Al}_{2} \mathrm{O}_{3}$ column.

The products captured in a multiposition sampling valve were sequentially injected to ensure sufficient analyzing times. The temperature of the column was maintained at $353 \mathrm{~K}$ for $5 \mathrm{~min}$ and then increased to $513 \mathrm{~K}$ at a ramping rate of $10 \mathrm{~K} \mathrm{~min}^{-1}$. The total analyzing time for each run was 50 minutes. The conversion of 1-butene was defined as the percentage of 1-butene consumed in the reactions and the selectivity of a given product was defined as the percentage of 1-butene consumed for its production. 


\section{Results and Discussion}

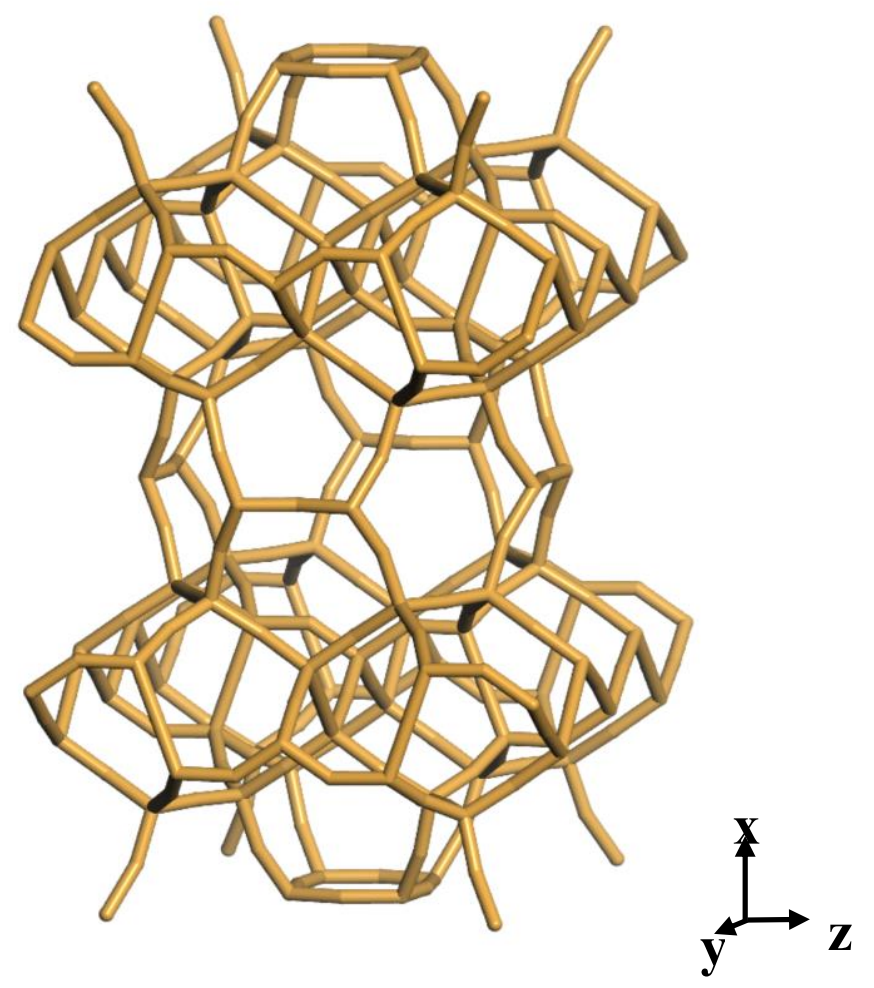

Scheme S1. NON topology.

NON is a cage-type zeolite with ony 6-MR window as the largest aperture, and thus it is considered as a nonporous zeolite. 


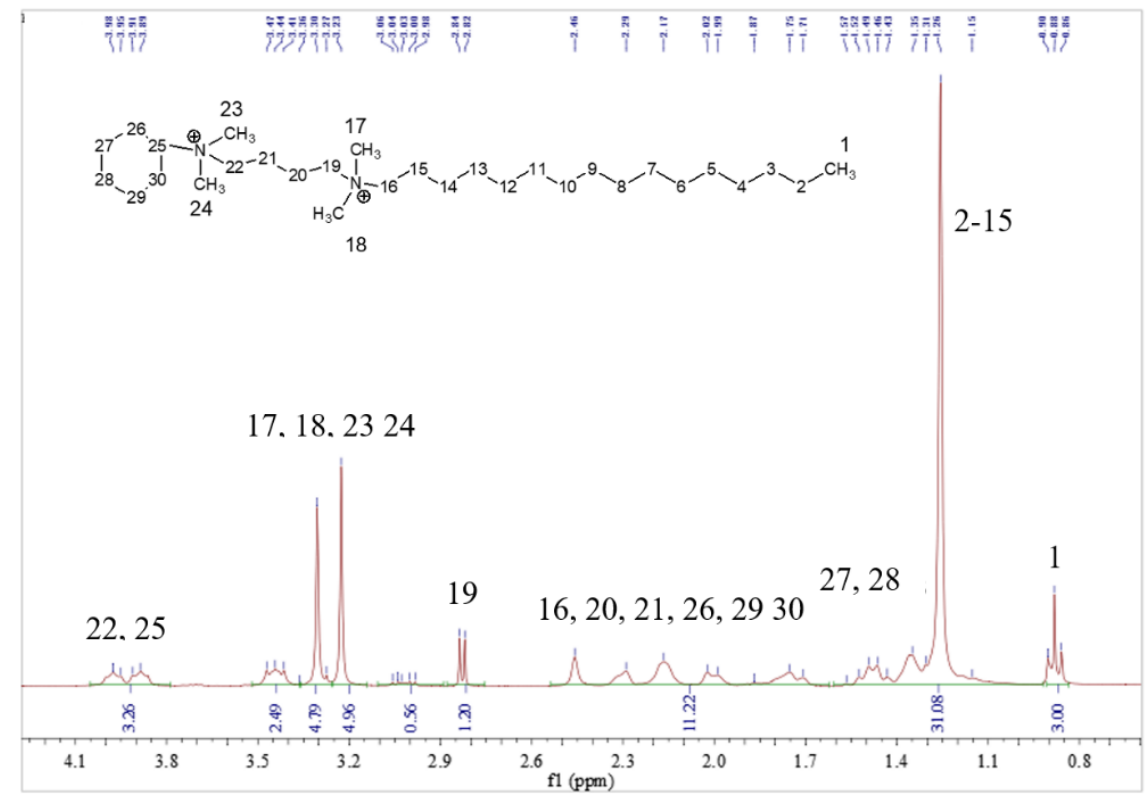

Figure S1. ${ }^{1} \mathrm{H}$ NMR spectrum of Che-4-16 in $\mathrm{D}_{2} \mathrm{O}$. 


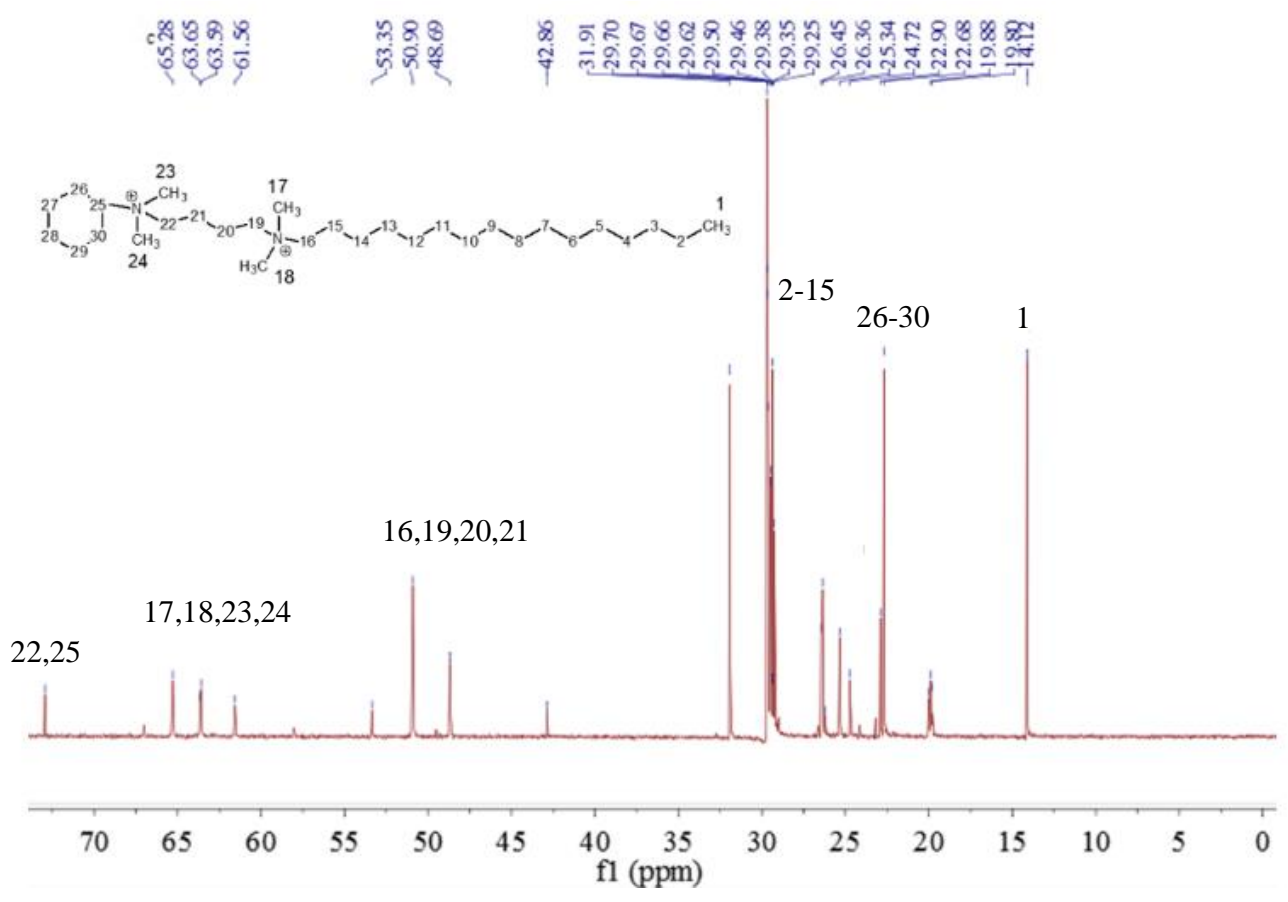

Figure S2. ${ }^{13} \mathrm{C}$ NMR spectrum of Che-4-16 in $\mathrm{D}_{2} \mathrm{O}$.

NON zeolite with ordered defect structure (named as ECNU-27) was prepared by Gemini-type oganic structuredirecting agent (OSDA) of $\mathrm{C}_{16} \mathrm{H}_{33}-\mathrm{N}^{+}-\left(\mathrm{CH}_{3}\right)_{2}-\mathrm{C}_{4} \mathrm{H}_{8}-\mathrm{N}^{+}-\left(\mathrm{CH}_{3}\right)_{2}$-cylohexyl-ammonium (Che-4-16). The ${ }^{1} \mathrm{H}$ and ${ }^{13} \mathrm{C}$ NMR spectra shown in Figure S1 and Figure S2 indicated that the OSDA of Che-4-16 was successfully synthesized. 


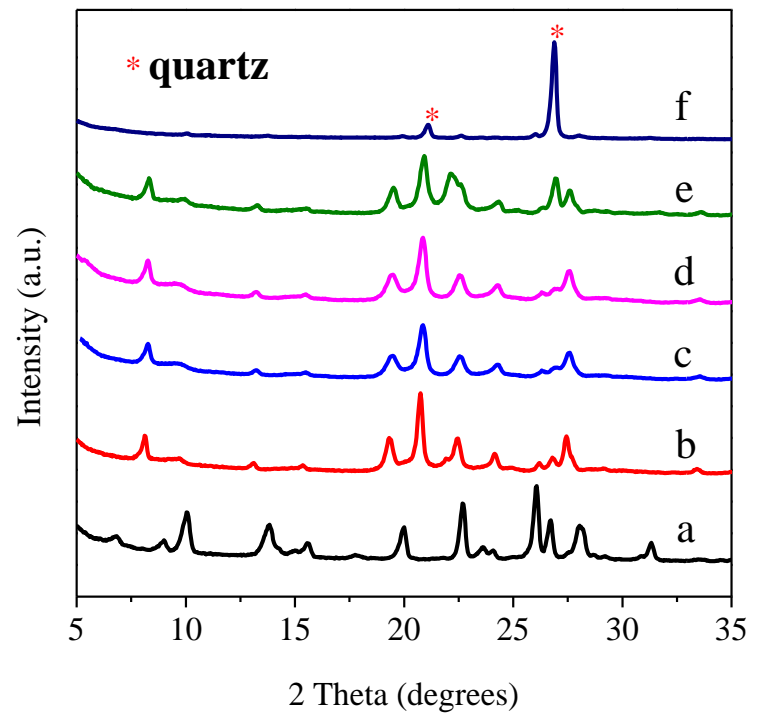

Figure S3. PXRD patterns $(\lambda=1.5418 \AA)$ of the products synthesized with the Si/Al ratio of 10 (a), 20 (b), 30 (c), 40 (d), 50 (e) and 60 (f). Other crystallization conditions: $\mathrm{H}_{2} \mathrm{O} / \mathrm{Si}=40, \mathrm{OSDA} / \mathrm{Si}=0.1, \mathrm{Na} / \mathrm{Si}=0.2,443 \mathrm{~K}, 14 \mathrm{~d}$, dynamic.

ECNU-27 could be obtained with the Si/Al molar ratio ranging between 20 and 40 in the synthetic gels (Figure S3, $b$ and c). As the Si/Al ratio was lower than 20, MOR phase was obtained (Figure S3a). At higher Si/Al ratios of 50 - 60, the quartz phase appeared and the ECNU-27 phase disappeared gradually (Figure S3, d-f). 


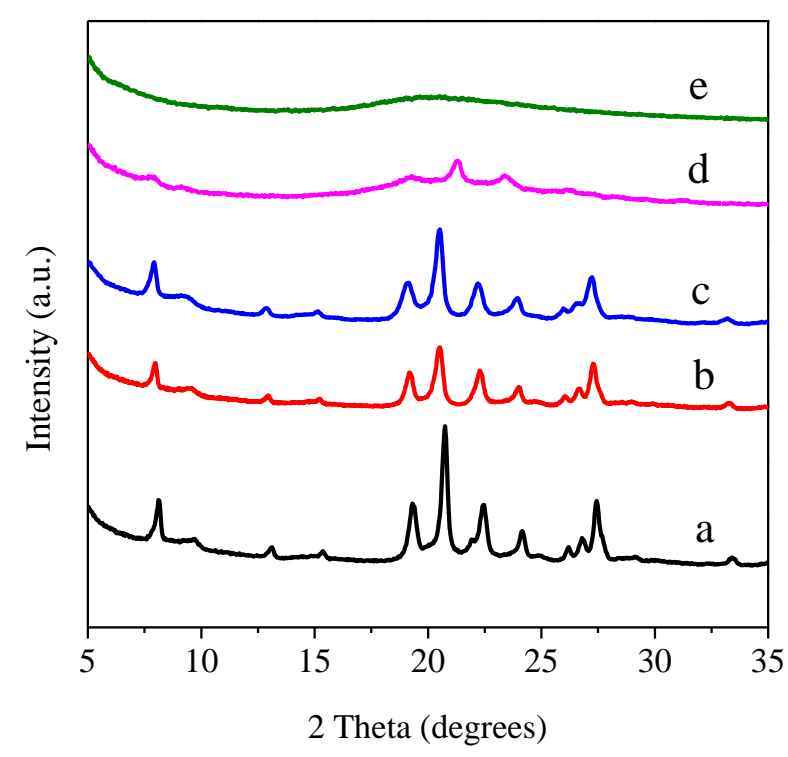

Figure S4. PXRD patterns ( $\lambda=1.5418 \AA$ ) of the products synthesized with $\mathrm{H}_{2} \mathrm{O} / \mathrm{Si}$ ratio of 20 (a), 30 (b), 40 (c), 50 (d) and 60 (e). Other crystallization conditions: $\mathrm{Si} / \mathrm{Al}=30, \mathrm{SDA} / \mathrm{Si}=0.1, \mathrm{Na} / \mathrm{Si}=0.2,443 \mathrm{~K}, 14 \mathrm{~d}$, dynamic.

The crystallinity of the product decreased obviously as the water content increased. ECNU-27 was readily crystallized at the $\mathrm{H}_{2} \mathrm{O} / \mathrm{Si}$ ratios of $20-40$. 


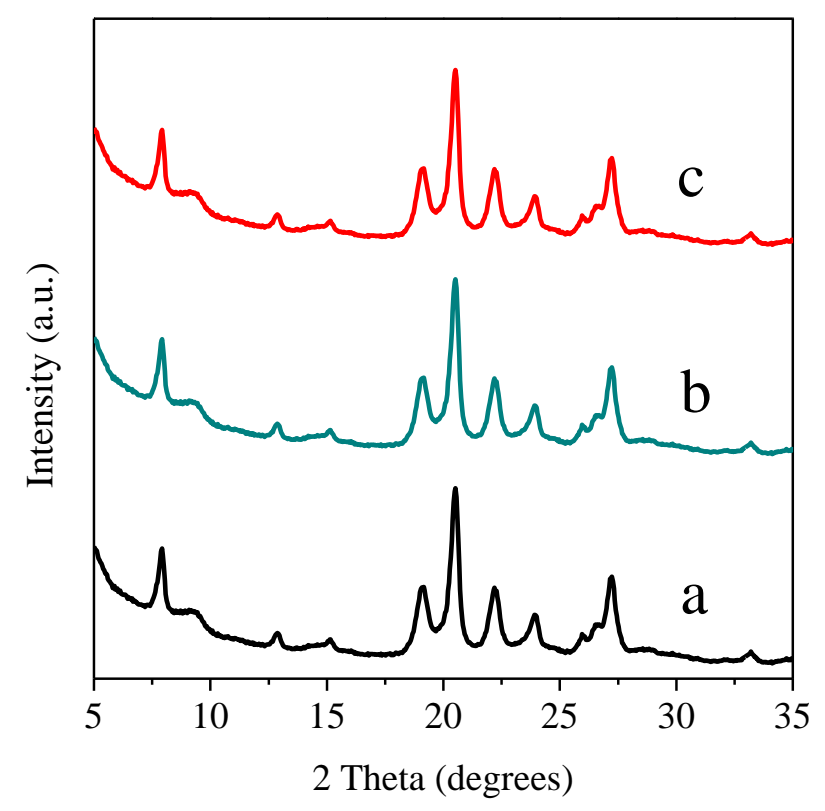

Figure S5. PXRD patterns $(\lambda=1.5418 \AA$ ) of as-made ECNU-27(a), calcined ( $873 \mathrm{~K}$ for 6 hours) (b) and hydrothermal treated ECNU-27. The hydrothermal treatment was carried out under $100 \%$ steaming at $1123 \mathrm{~K}$ for 8 hours.

The PXRD patterns of ECNU-27 in as-made, calcined and hydrothermally treated forms are shown in Figure S5. The framework structure remained stable after calcination and further severe steaming treatment, indicating ECNU-27 was highly thermal and hydrothermal stable. 

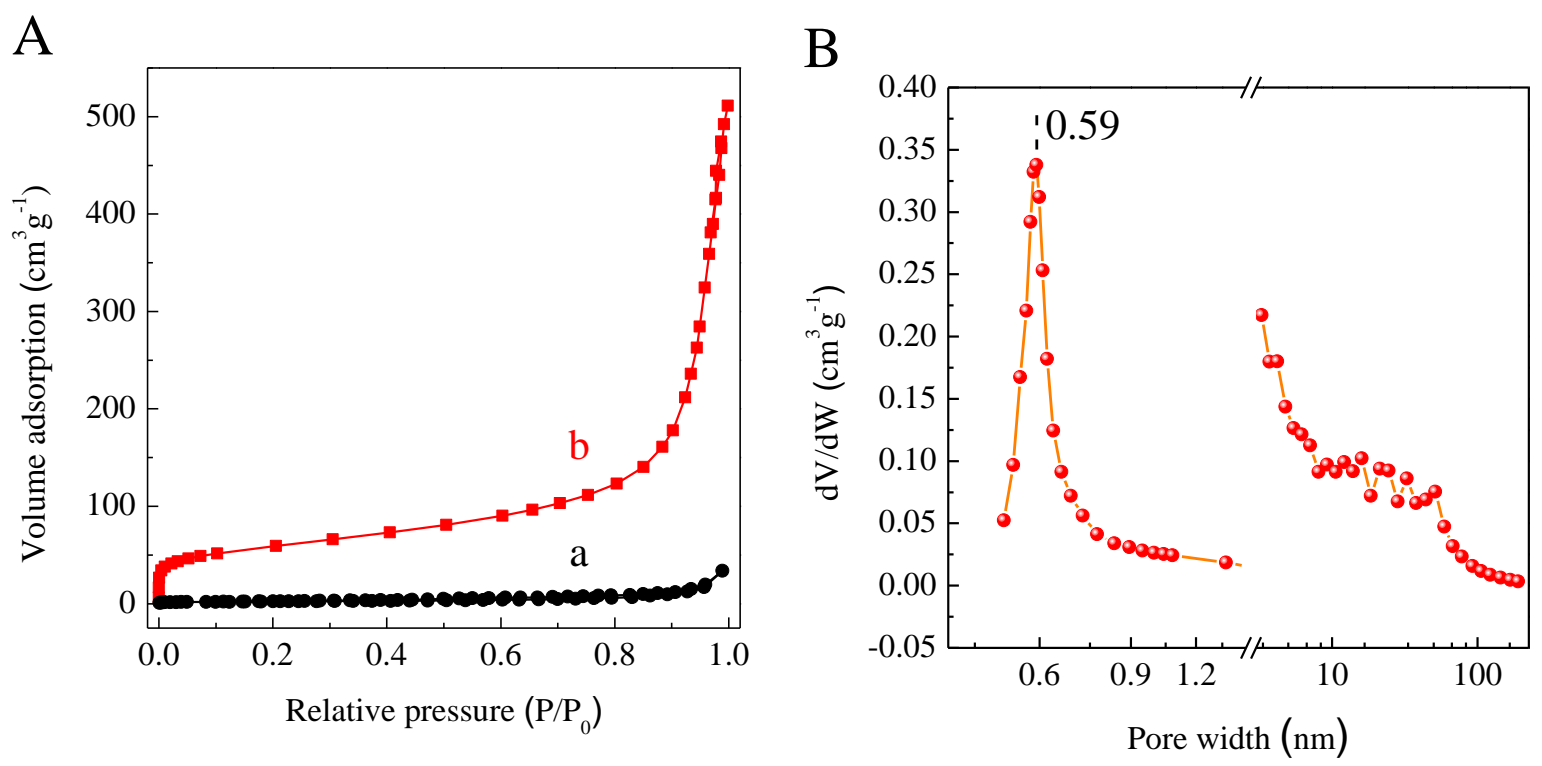

Figure S6. (A) $\mathrm{N}_{2}$ sorption isotherms for conventional NON (a) and ECNU-27 (b); (B) the pore size distribution of ECNU-27 calculated by Horvarth-Kawazoe method from Ar adsorption isotherm (micropore region) and BJH method from $\mathrm{N}_{2}$ adsorption isotherm (mesopore region).

Conventional NON is obviously a nonporous material, as it showed almost no nitrogen adsorption capacity in the whole relative pressure region, and extremely low specific surface area and micropore volume. On the contrary, ECNU-27 showed type IV $N_{2}$ sorption isotherm and multilayered adsorption behavior, which demonstrated the presence of both micropores and mesopores. Furthermore, the micropore size distribution of ECNU-27 was centered at $5.9 \AA$, which was close to that of 12-R zeolites. 

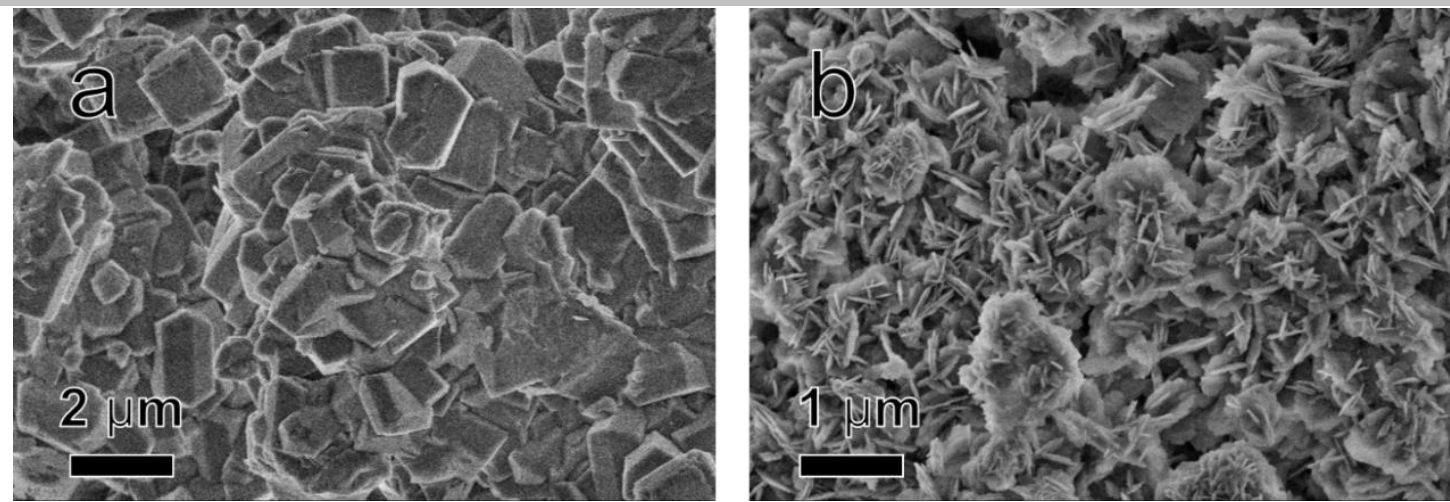

Figure S7. SEM images of NON (a) and ECNU-27 (b).

Unlike conventional NON-zeolite with cubic morphology, ECNU-27 was composed of smaller crystals with nanosheet-like morphology. 


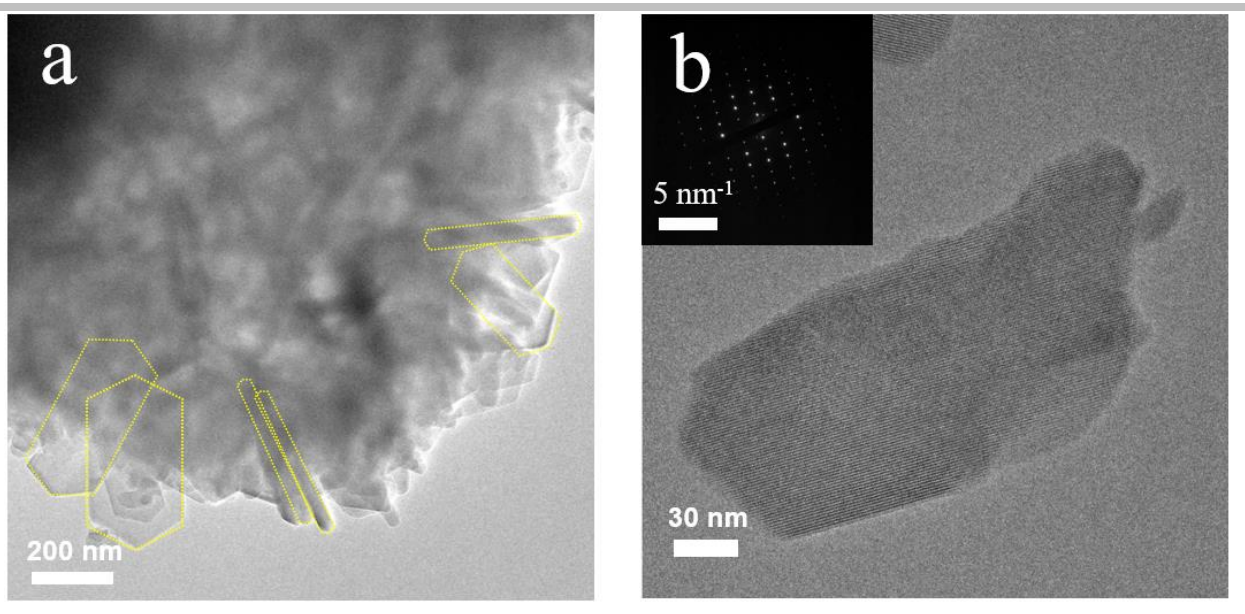

Figure S8. TEM images of ECNU-27 with the crystal outlines framed by yellow dotted lines (a), and the diffraction pattern taken along the thinnest direction was perpendicular to (010) crystal plane (b), indicating the thinnest direction was along the $b$ axis.

The TEM images of ECNU-27 revealed the nanosheet-like morphology with the thinnest direction along the $b$ axis, indicating an oriented growth was proceeded with the assistance of Gemini-type OSDA. 


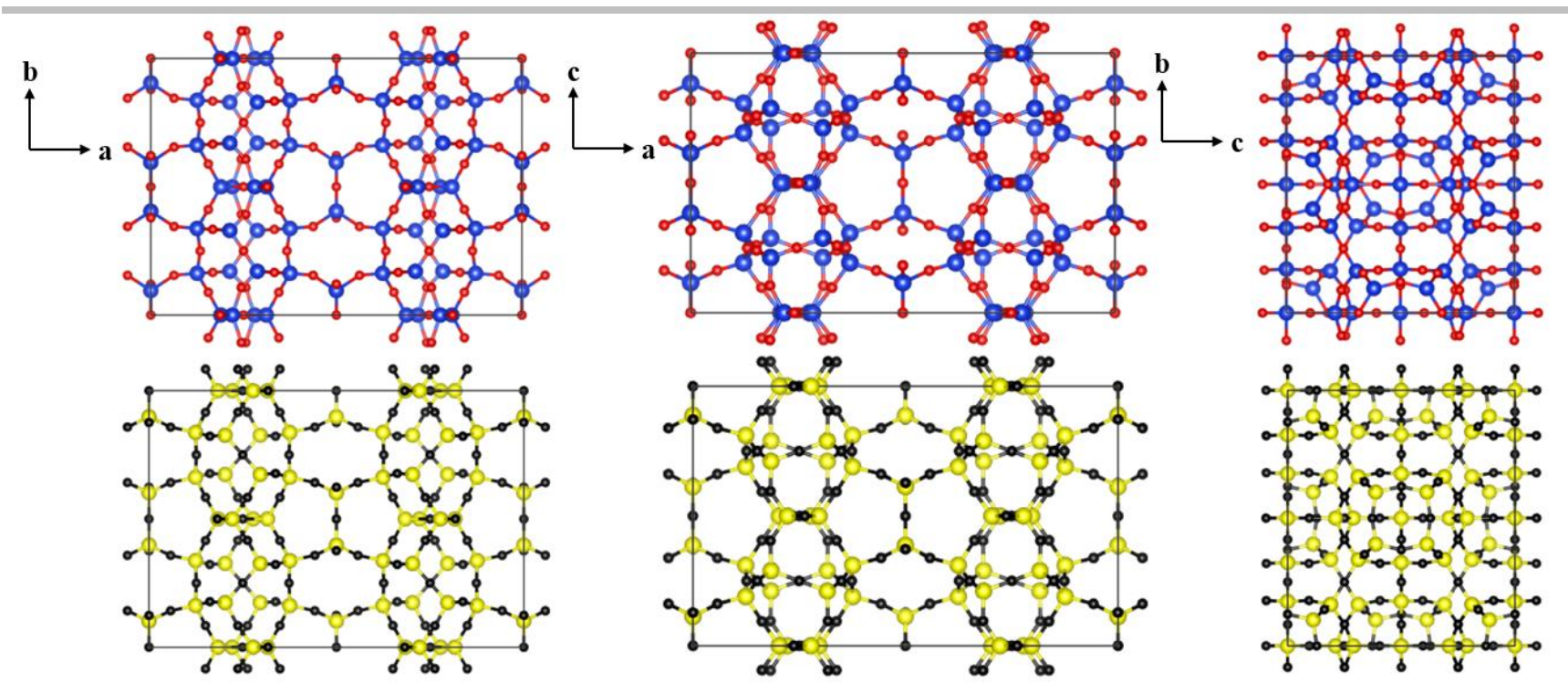

Figure S9. Projections along different direction of theoretical NON structure (top) and the solved ECNU-27 structure from 3D-EDT data (bottom).

The unit cell parameters of ECNU-27 were determined as $a=22.281 \AA, b=15.403 \AA$ and $c=13.649 \AA$ with $\alpha$ $=\beta=\gamma=90^{\circ}$, which matched well with the theoretical values of NON zeolite. The reflection conditions satisfied hkl: $h+k=2 n, k+l=2 n$ and $h+l=2 n$, suggesting space groups of F222, Fmm2 and Fmmm. The ab initio structure solution of ECNU-27 was obtained using direct methods, which is in accord with the NON type zeolite. 

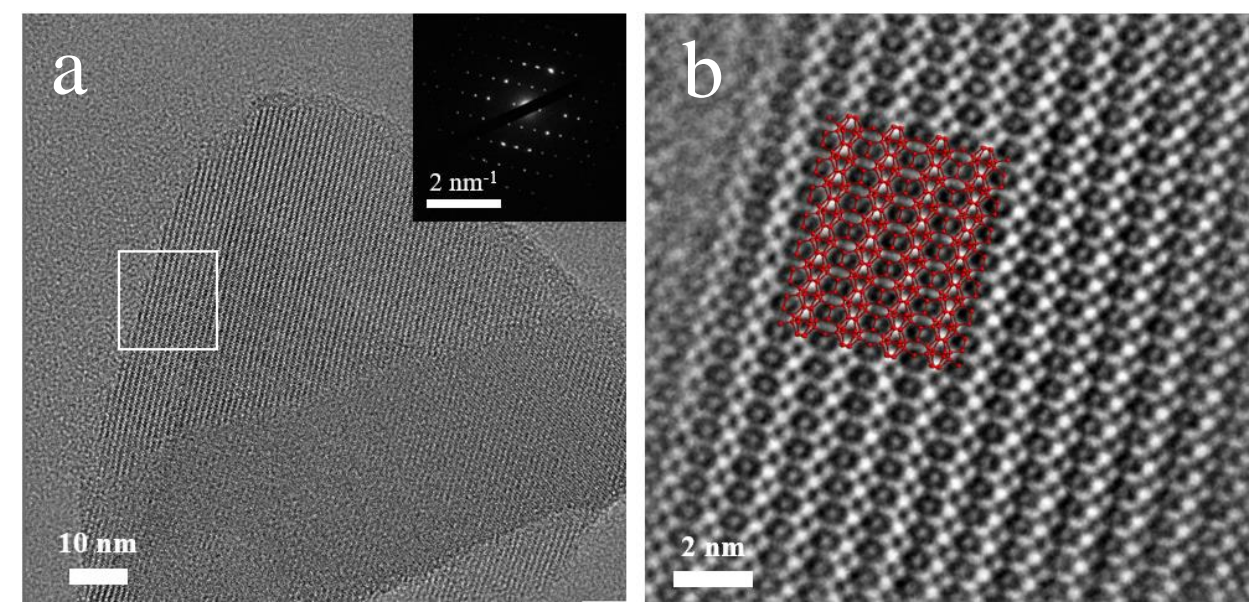

Figure S10. HRTEM image of ECNU-27 along [010] direction (a) and its magnified ABSF filtered image in the selected white box area (b).

HRTEM image along [010] direction indicated that the strcuture of ac plane of ECNU-27 highly matched with the structure model of NON, which is corresponding to the long-range periodicity of ac plane in the 3D-EDT data. 

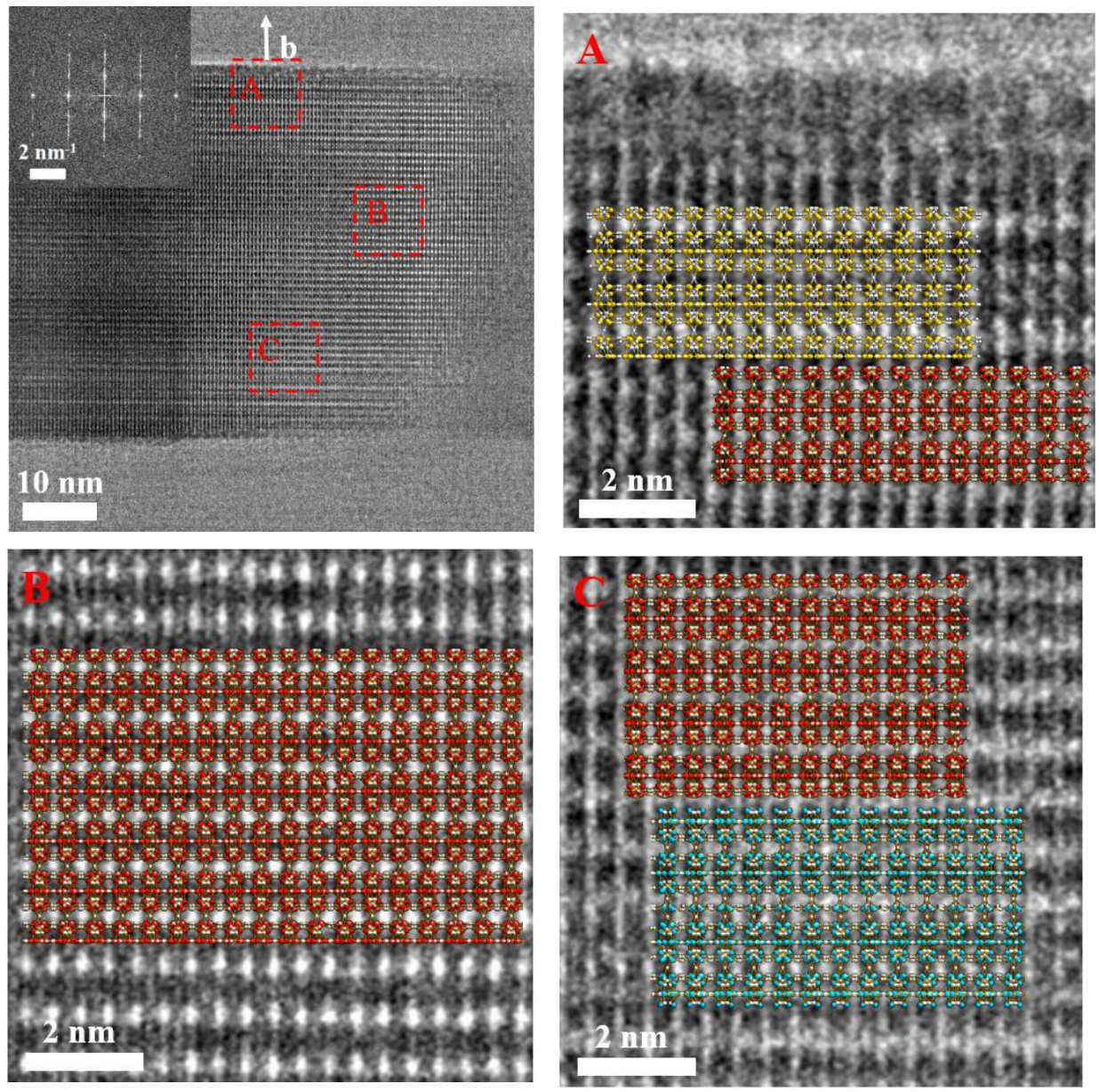

Figure S11. HRTEM image of ECNU-27 along [102] direction (up left) and related magnified images of differently selected red box areas with fitted structure model (A - C)

The structural change of ECNU-27 along b aixs compared to conventional NON strcuture was investigated by taking HRTEM images along [102] direction, and the obvious diffuse streaks in FFT distinctly demonstrated the loss of periodicity. Magnified images in different red box areas were shown with fitted structure model, which revealed that the loss of periodicity was caused by the planar defect. The measured lattice parameters $b_{A}=22.7$ $\AA$ and $b_{B}=25.1 \AA$ were also close to the NON-related structure models. 


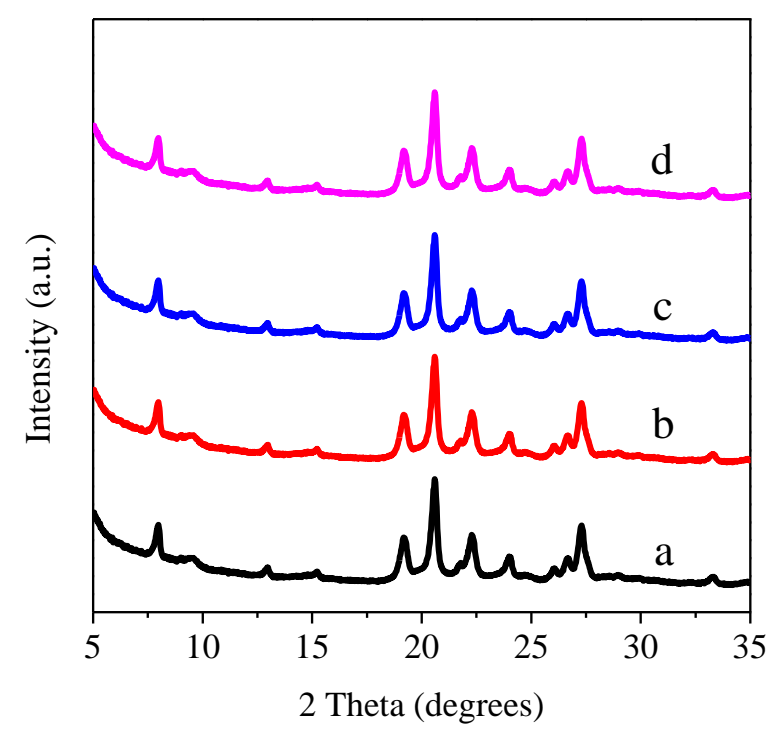

Figure S12. PXRD patterns of as-made ECNU-27-P (a), silylated ECNU-27-P (b) and their corresponding acid-treated samples with $2 \mathrm{M} \mathrm{HCl}$ aqueous solution (c and d). Acid treatment conditions: liquid to solid ratio, $50 \mathrm{~mL}: 1 \mathrm{~g}$; temp., $463 \mathrm{~K}$; time, $24 \mathrm{~h}$. Tetraethylorthosilicate (TEOS) was added to the mixture by $1 \mathrm{mmol}$ per gram of zeolites for silylation.

The silylation with TEOS was performed with the purpose to repair the defects in the ECNU-27 with Si atoms. However, the ECNU-27 structure was unchanged after silylation. Moreover, the dealumination process, meaning to cause more defects, did not arouse any structural change either. The results indicated that the loss of periodicity was mainly caused by the planar defects. 

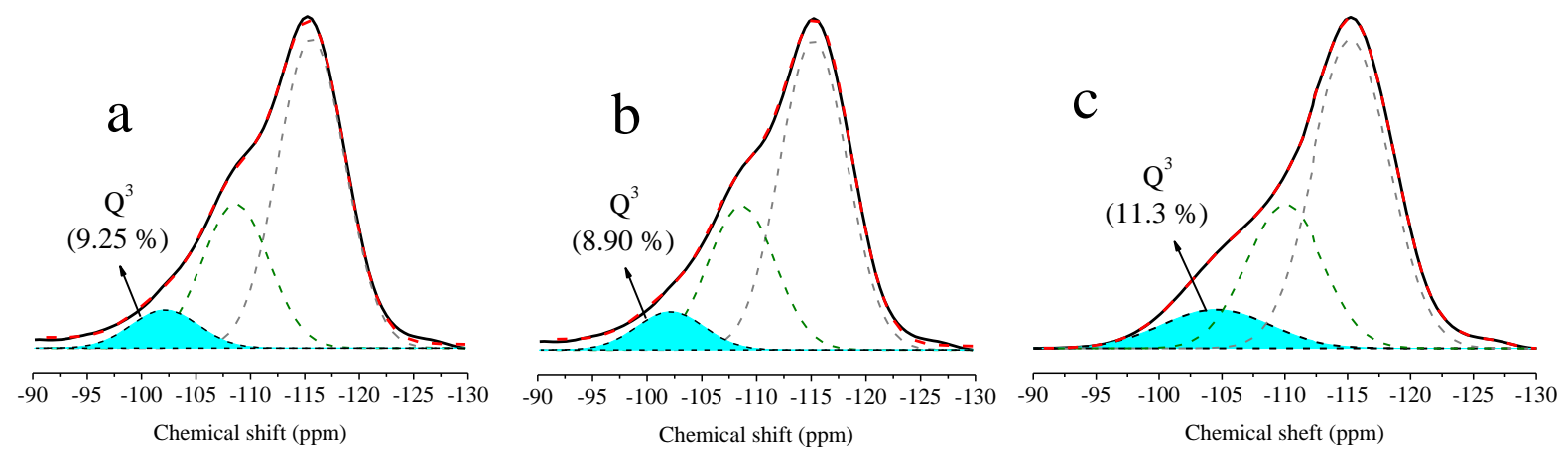

Figure S13. ${ }^{29}$ Si MAS NMR spectra (solid lines) and fitting results (dotted lines) of as-made ECNU-27-P (a), silylated ECNU-27-P (b) and acid-treated ECNU-27-P (c).

The ${ }^{29}$ Si MAS NMR spectra of as-made ECNU-27-P, silylated ECNU-27-P and acid-treated ECNU-27-P were shown in Figure S13. The main resonances in the range of -105 to $-120 \mathrm{ppm}$ were attributed to $Q^{4}$ group, whereas the resonances at -95 to $-105 \mathrm{ppm}$ were ascribed to $Q^{3}$ group. ${ }^{1-2}$ The relative peak area of $Q^{3}$ group for silylated ECNU-27-P was slightly lower than that of ECNU-27-P, indicating that very few intracrystal defects were eliminated upon silylation. The relative peak area of $Q^{3}$ group for acid-treated ECNU-27-P was higher than that for ECNU-27, indicative of more intracrystal defects formed in acid treatment. 

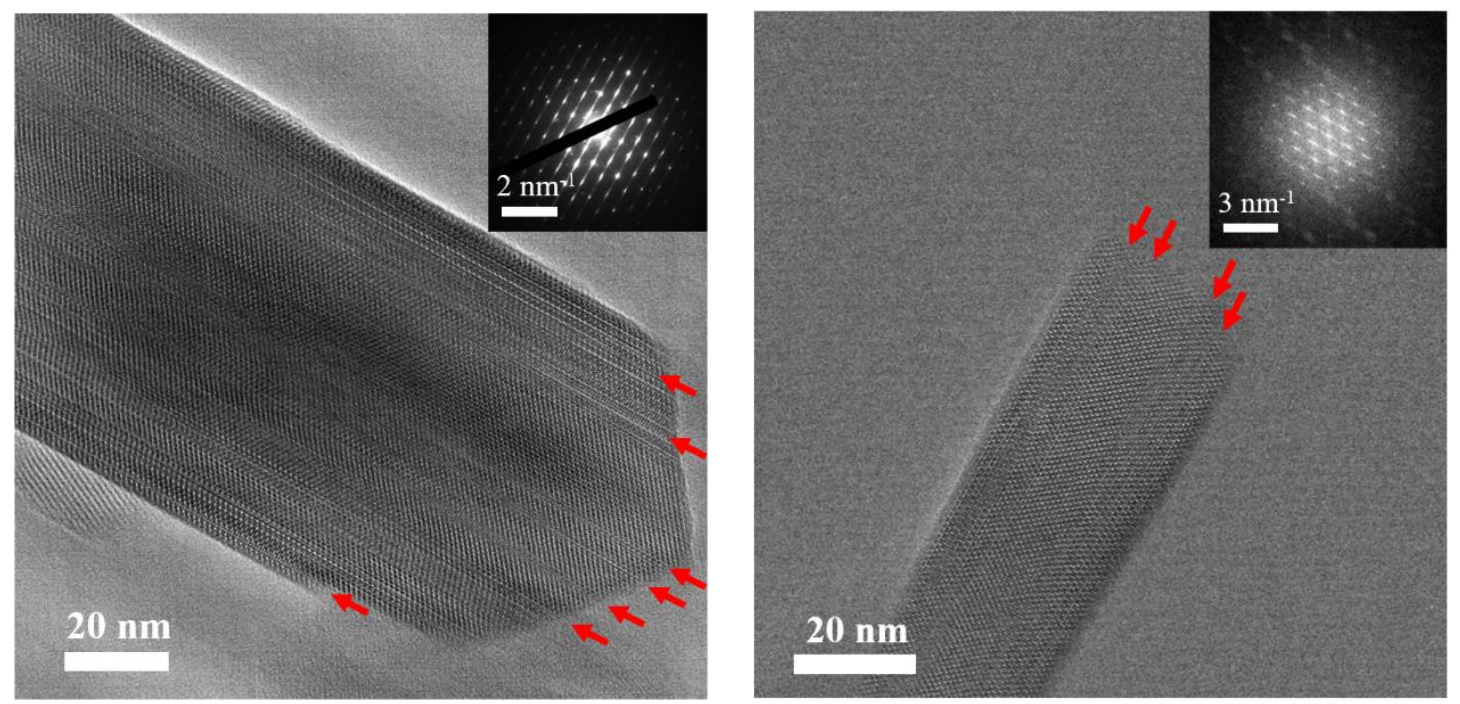

Figure S14. HRTEM images with low magnification along [101] direction of different ECNU-27 crystals. The micropore entrances generated by defects were labeled with red arrow. The random red arrows also indicated the random distribution of defects in different ECNU-27 crystals.

It should be mentioned that the mismatch during the linkage of structure units was totally random as the distribution of defect structure was different in every ECNU-27 crystal. Besides, the images with low magnification along [101] direction of different ECNU-27 crystals were taken to confirm the defect structure extended to the surface of crystal so that the guest molecules are able to diffuse into crystal through the defectgenerated micropores. 

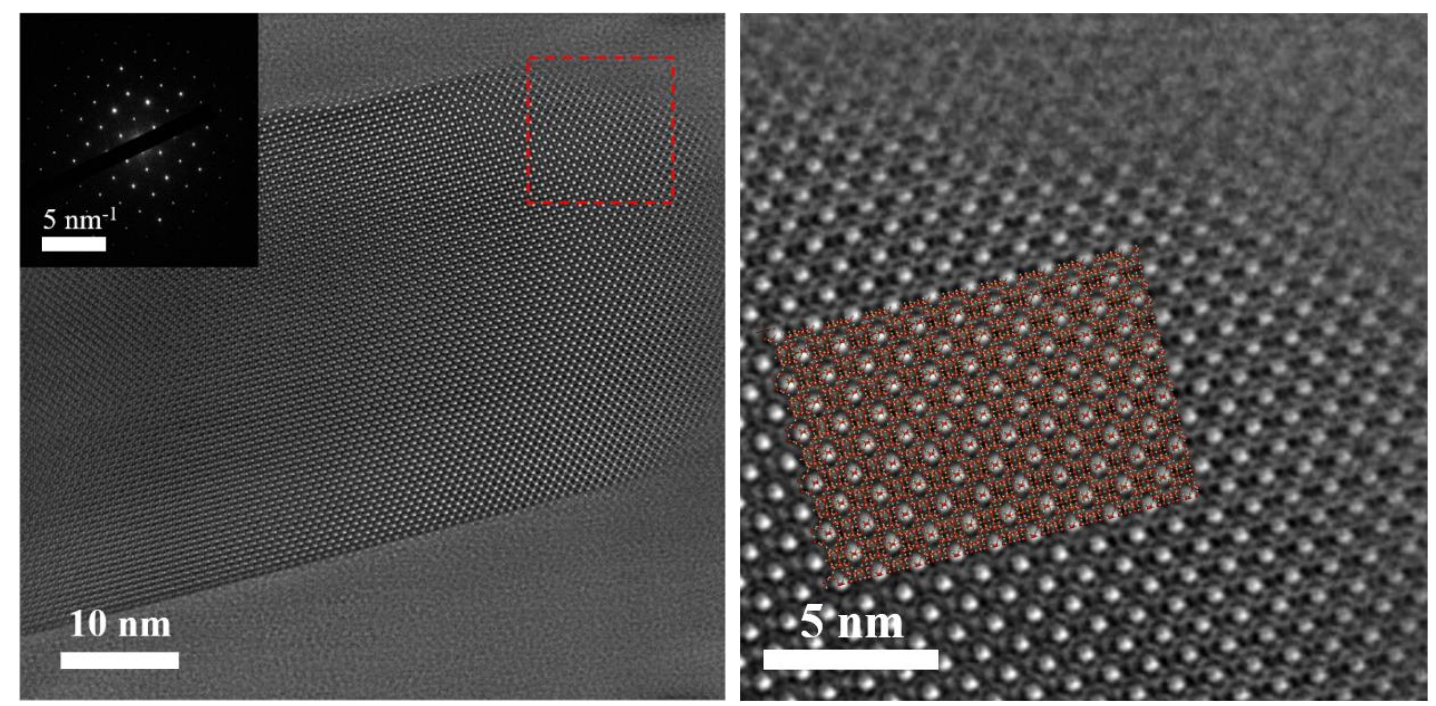

Figure S15. ABSF filtered HRTEM image of a crystal with pure NON phase in ECNU-27 along [101] and its magnified image in the selected red box area.

We could accidentally find pure NON crystal in ECNU-27 powder. 

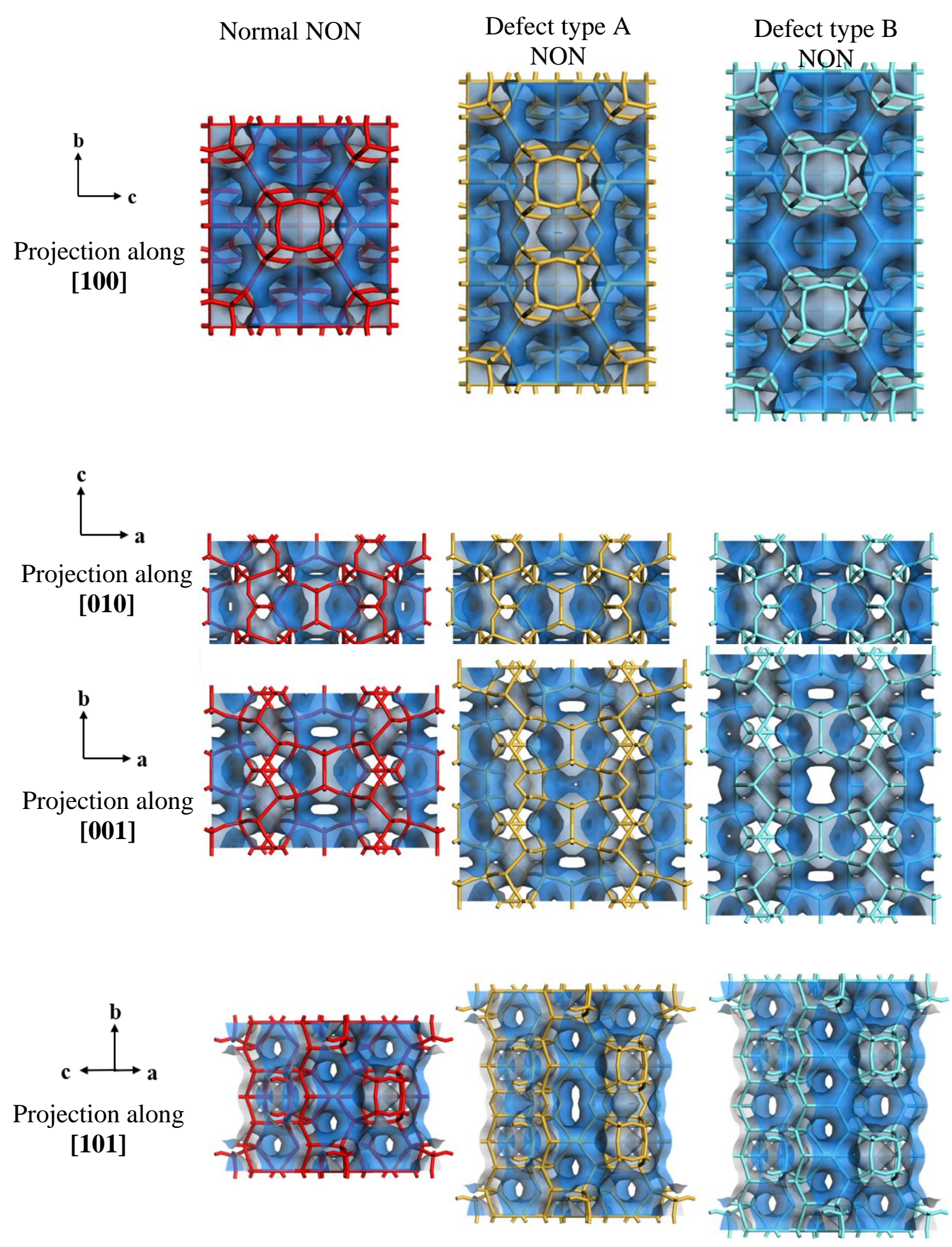

Figure S16. The structures of normal NON, defect type A NON and defect type B NON along [100], [010], [001] and [101] directions.

The connolly surface of ECNU-27 was calculated by Material Studio to exhibit the micropores channel of zeolite structure. The unit-cell parameter $b$ was $b_{A-N O N}=23.684 \AA$ and $b_{B-N O N}=26.398 \AA$ for two NON-related structures, respectively, with a and c remained the same as NON. 


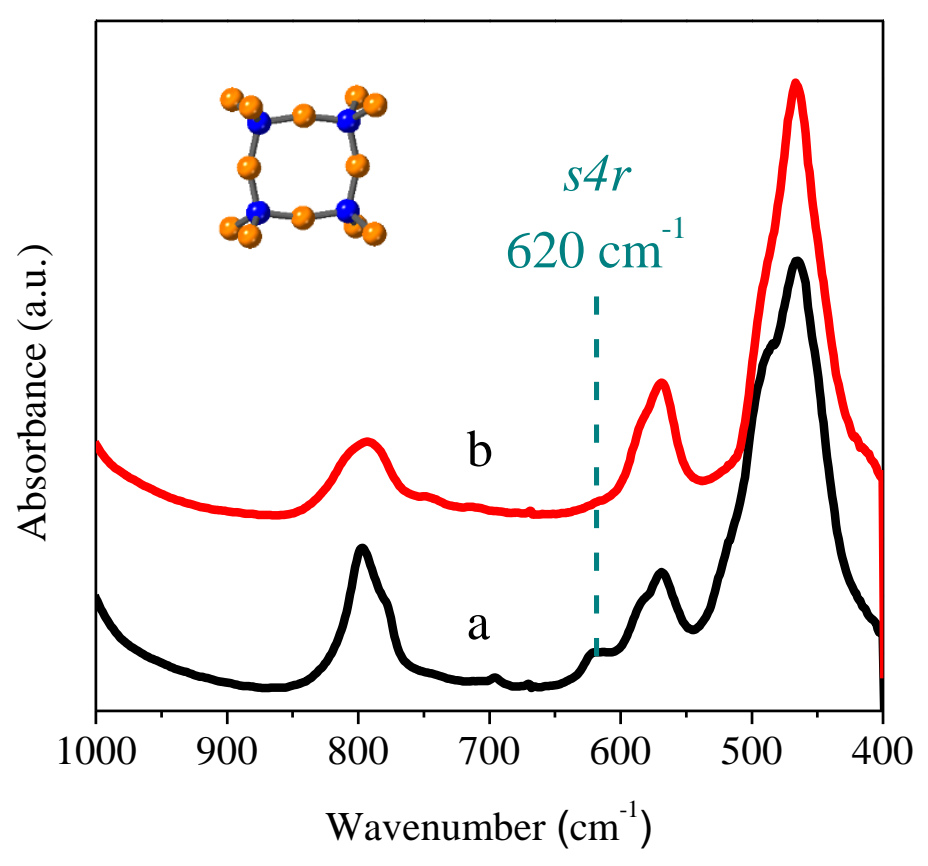

Figure S17. FT-IR spectra in framework vibration region of NON (a) and ECNU-27 (b).

The band at $620 \mathrm{~cm}^{-1}$, attributed to the 4-R building units in NON framework ${ }^{3-4}$, was almost invisible for ECNU-27. This indicated that the amount of four-member rings in ECNU-27 was significantly reduced compared to that of NON. These results were consistent with that of the UV-Raman investigation. 

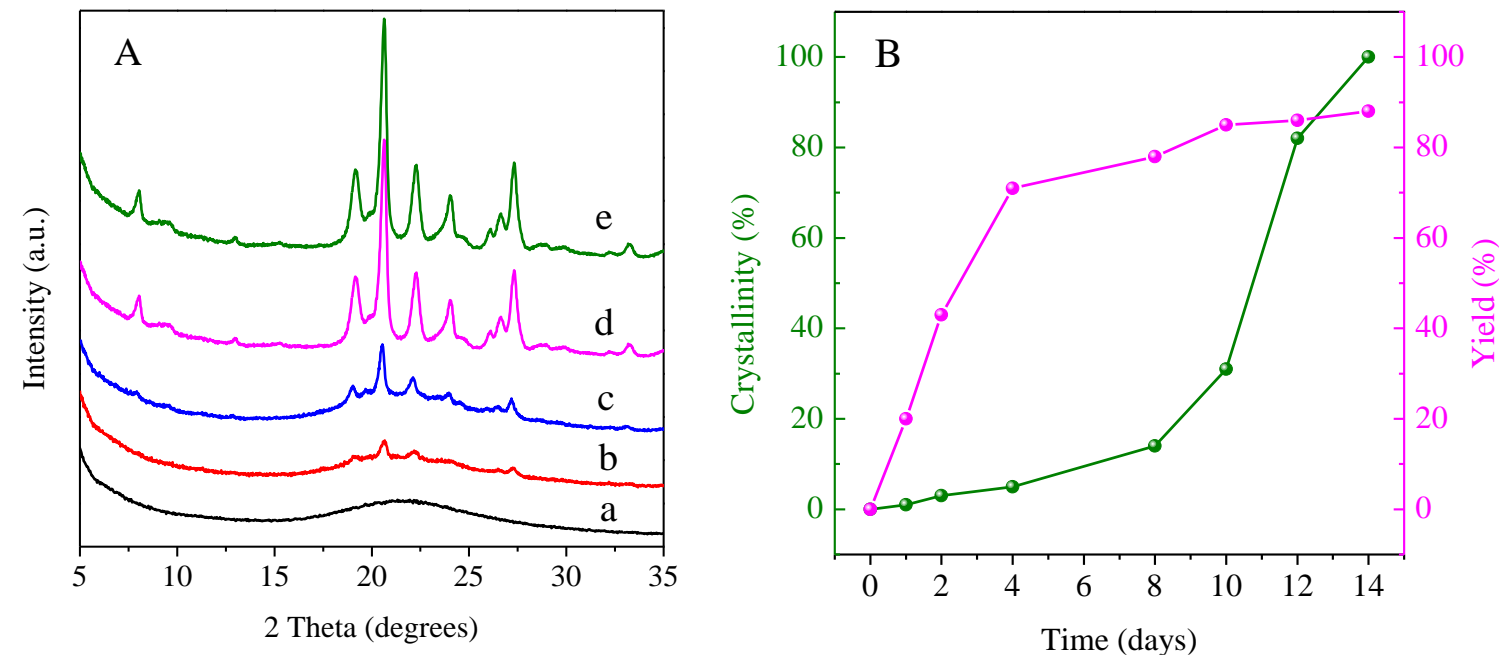

Figure S18. PXRD patterns of as-synthesized samples (A) and time-dependent curves of crystallinity and product yield (B) during the hydrothermal synthesis of ECNU-27 for 0 (a), 96 (b), 192 (c), 288 (d) and 336 (e) hours. Crystallization conditions: $\mathrm{Si} / \mathrm{Al}=30 ; \mathrm{H}_{2} \mathrm{O} / \mathrm{Si}=40 ; \mathrm{SDA} / \mathrm{Si}=0.1 ; \mathrm{Na} / \mathrm{Si}=0.2 ; 443 \mathrm{~K}$; dynamic.

To assess the degree of crystallinity, the crystallization products were obtained with different crystallization times (between $0 \mathrm{~h}$ and $504 \mathrm{~h}$ ) at $443 \mathrm{~K}$. The relative crystallinity of ECNU-27 increased slowly at the beginning of crystallization ( $<4$ days), while the yield of ECNU-27 could reach $80 \%$. As prolonging the crystallization time, the relative crystallinity of ECNU-27 increased rapidly until complete crystallization. 

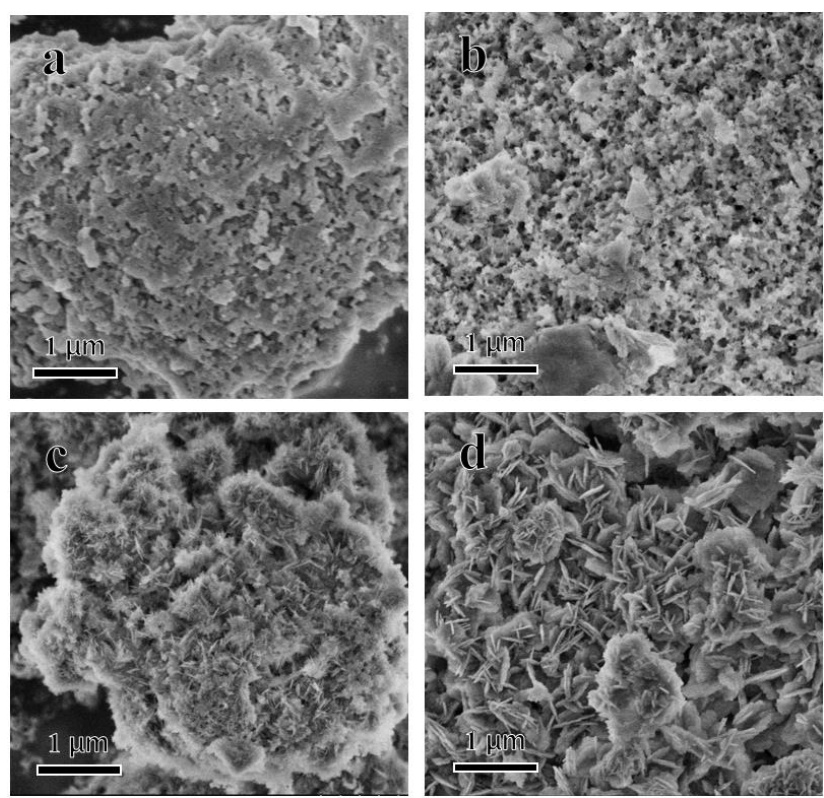

Figure S19. SEM images of as-synthesized samples during the hydrothermal synthesis of ECNU-27-P for 3 (a), 6 (b), 9 (c) and 12 (d) days. Crystallization conditions: $\mathrm{Si} / \mathrm{Al}=30 ; \mathrm{H}_{2} \mathrm{O} / \mathrm{Si}=40 ; \mathrm{SDA} / \mathrm{Si}=0.1 ; \mathrm{Na} / \mathrm{Si}=0.2 ; 443$ $\mathrm{K}$; dynamic.

As shown in Figure S18a, the foamed amorphous aluminosilicate was observed at the beginning of the crystallization ( $<3$ days). The nanosheets morphology products were found when the samples were crystallized after 6 days (Figure $S 18, b-d)$. The thickness of nanosheets substantially remained the same as the crystallization time increasing, indicating the orientated growth during this period. 


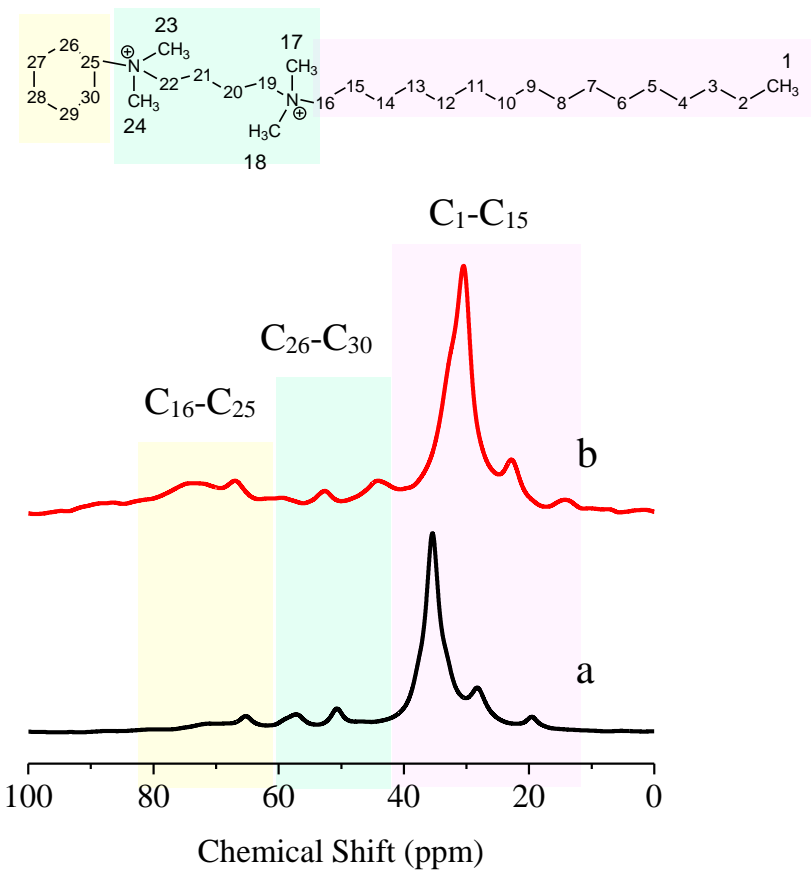

Figure S20. Solid-state ${ }^{13} \mathrm{C}$ MAS NMR spectra of pure Che-4-16 in bromide form (a) and Che-4-16 occluded in as-made ECNU-27-P (b).

The ${ }^{13} C$ MAS NMR spectrum of as-made ECNU-27 was similar to that of pure Che-4-16, indicating that the OSDA molecules remained intact in the crystallization process. 

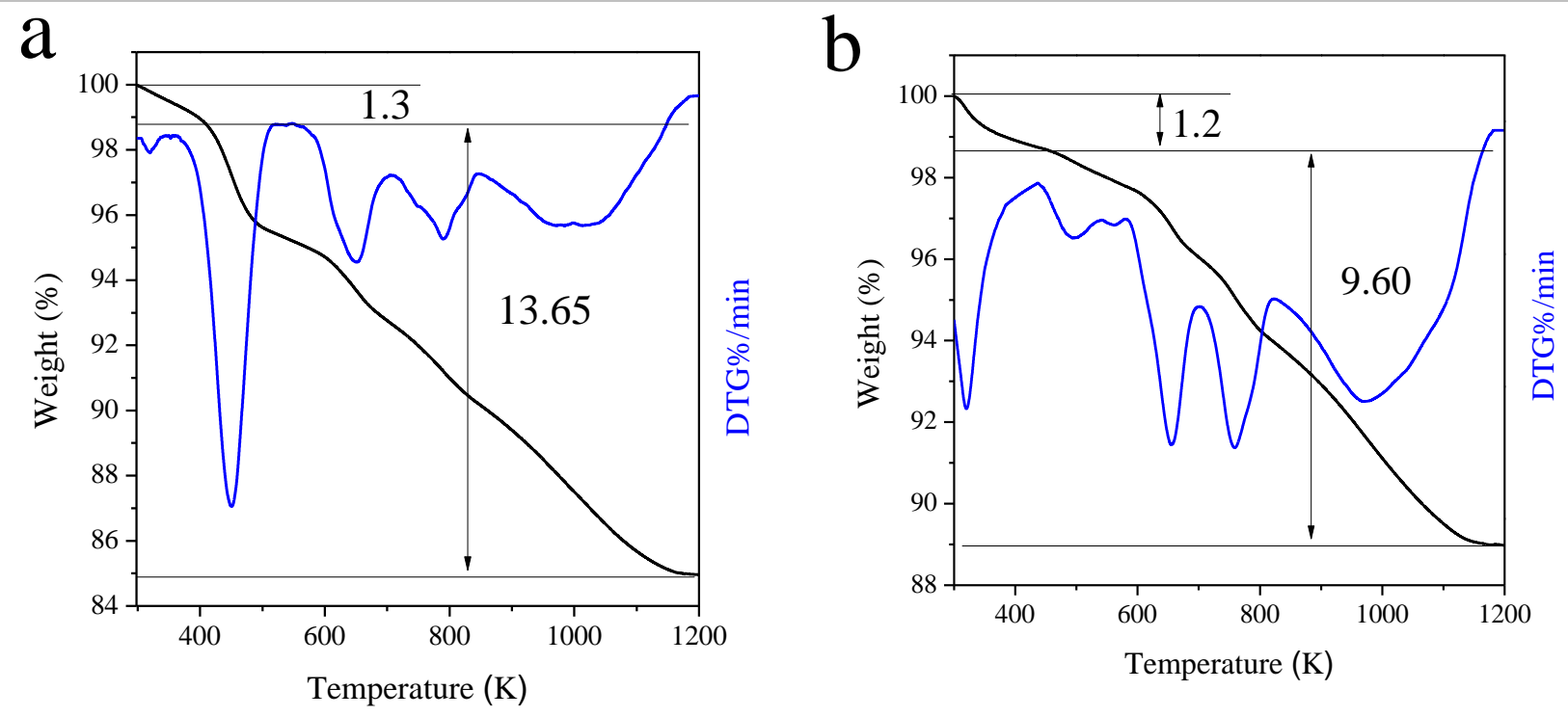

Figure S21. TG curves of as-made ECNU-27 (a) and after washing with $2 \mathrm{M} \mathrm{HCl} /$ ethanol solution (b). Acid treatment conditions: liquid to solid ratio, $50 \mathrm{~mL}: 1 \mathrm{~g}$; temp., $413 \mathrm{~K}$; time, $24 \mathrm{~h}$.

The TG curves of as-made ECNU-27 and the acid-treated ones were measured to reveal the location of OSDA inside zeolites. The decreased weight loss occurred in the low temperature region (below $450 \mathrm{~K}$ ) was caused by removing free water and crystal water from as-made ECNU-27. After washing with HCl/ethanol solution under high temperature, about 71 wt.\% of organic species still remained in the zeolite framework, implying the strong interaction between OSDAs and inorganic framework. 


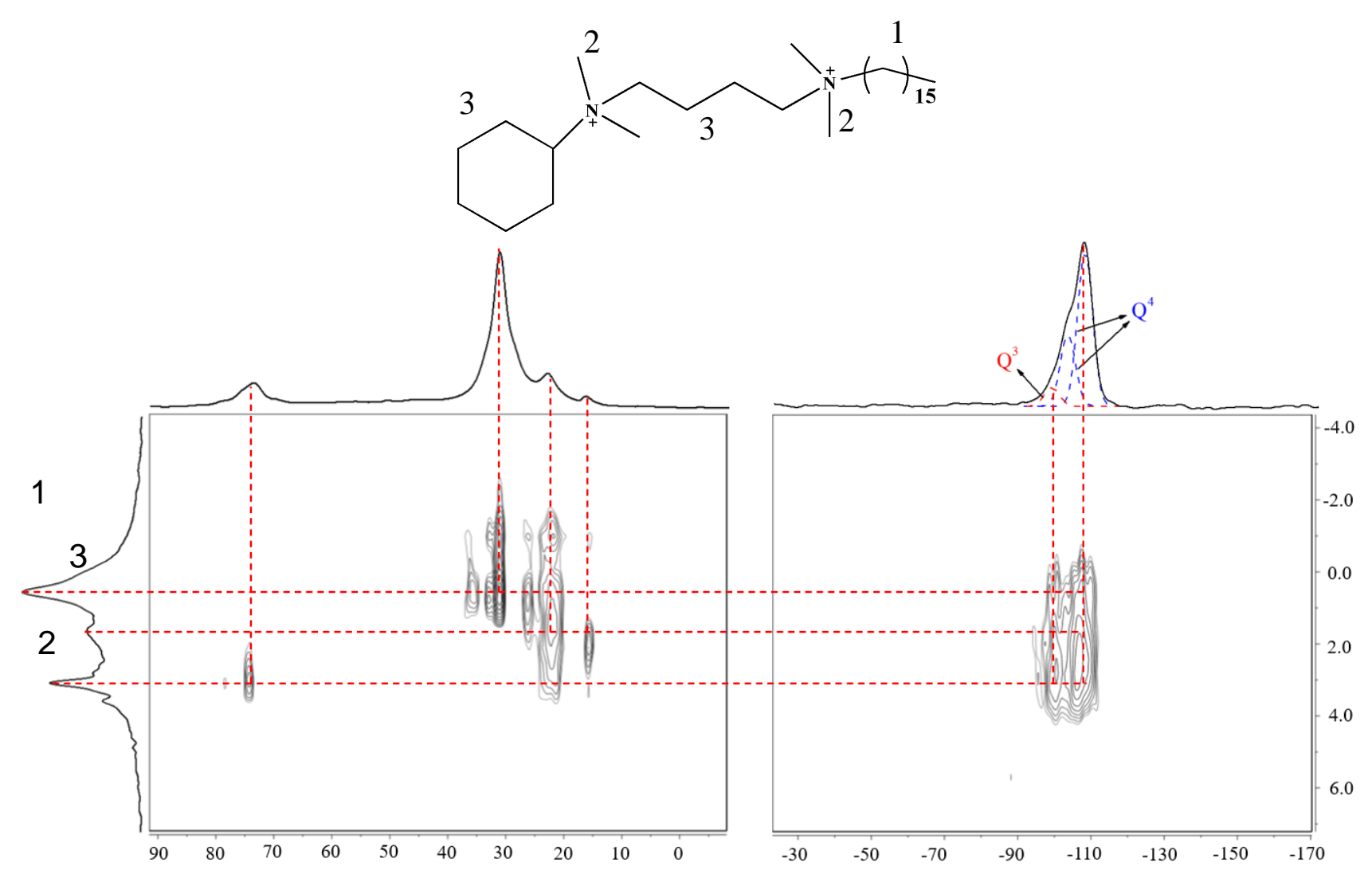

Figure S22. ${ }^{1} \mathrm{H}^{-13} \mathrm{C}$ (left) and ${ }^{1} \mathrm{H}-{ }^{29} \mathrm{Si}$ (right) HETCOR NMR spectra of as-made ECNU-27 (Si/Al=28). Onedimensional ${ }^{13} \mathrm{C}$ CP/MAS, ${ }^{29} \mathrm{Si} \mathrm{CP} / \mathrm{MAS}$ and ${ }^{1} \mathrm{H}$ MAS NMR spectra are shown on the axes, whereas the dotted lines in ${ }^{29} \mathrm{Si} \mathrm{CP} / \mathrm{MAS}$ spectrum show the deconvoluted results for $\mathrm{Q}^{3}$ and $\mathrm{Q}^{4}$ groups.

The spatial proximity between the framework of ECNU-27 and OSDA molecules can effectively observed by ${ }^{1} \mathrm{H}$ ${ }^{29} \mathrm{Si}$ HETCOR NMR spectra ${ }^{5-6}$. The resonances at ca. $3.2 \mathrm{ppm}$ in ${ }^{1} \mathrm{H}$ MAS NMR spectrum was ascribed to the methylene $\left(\mathrm{CH}_{2}\right)$ and methyl $\left(\mathrm{CH}_{3}\right)$ species directly connected to the two quaternary ammonium cations in Che4-16 molecule, while the other two resonances at ca.0.5 and 1.8 ppm were ascribed to hydrophobic segments of OSDA. The main resonances in ${ }^{29} \mathrm{Si} C P / M A S N M R$ spectrum around -105 to $-120 \mathrm{ppm}$ were from the $Q^{4}$ group, whereas the resonances at -95 to -105 ppm were attributable to the $Q^{3}$ group ${ }^{1-2}$. The $Q^{4}$ groups derived from the skeleton of ECNU-27 had a strong interaction with both hydrophilic and hydrophobic segments of the OSDA, indicating that the OSDAs were embedded in the structure of ECNU-27 zeolite. The result suggested that the generation of staggered layer structure might be related to the blocking effect of long chain OSDA molecules. The $Q^{3}$ group in ${ }^{29}$ Si CP/MAS NMR spectrum related to the structural defects had strong interaction with the hydrophilic segment, indicating the structure-directing role of quaternary ammonium cations in the formation of ECNU-27. 


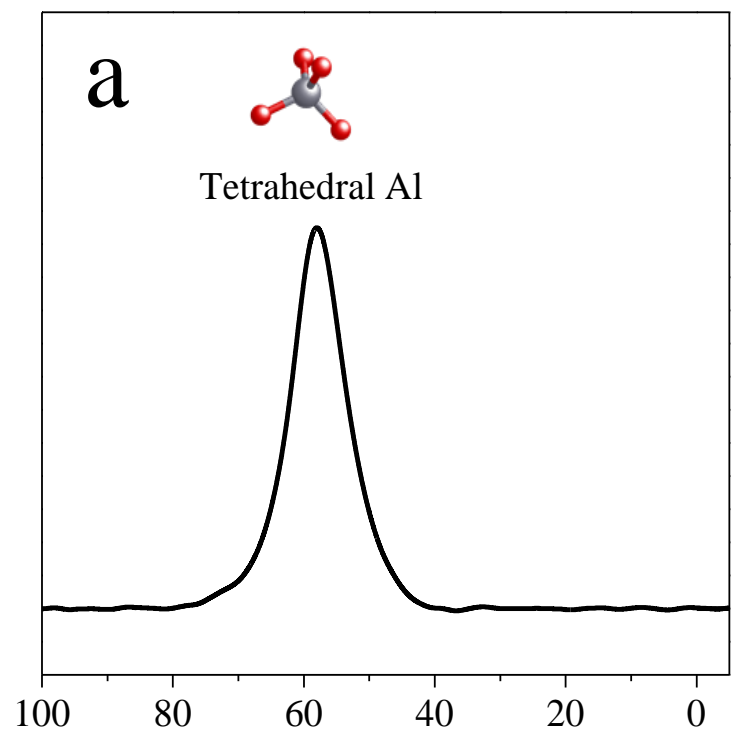

Chemical shift (ppm)

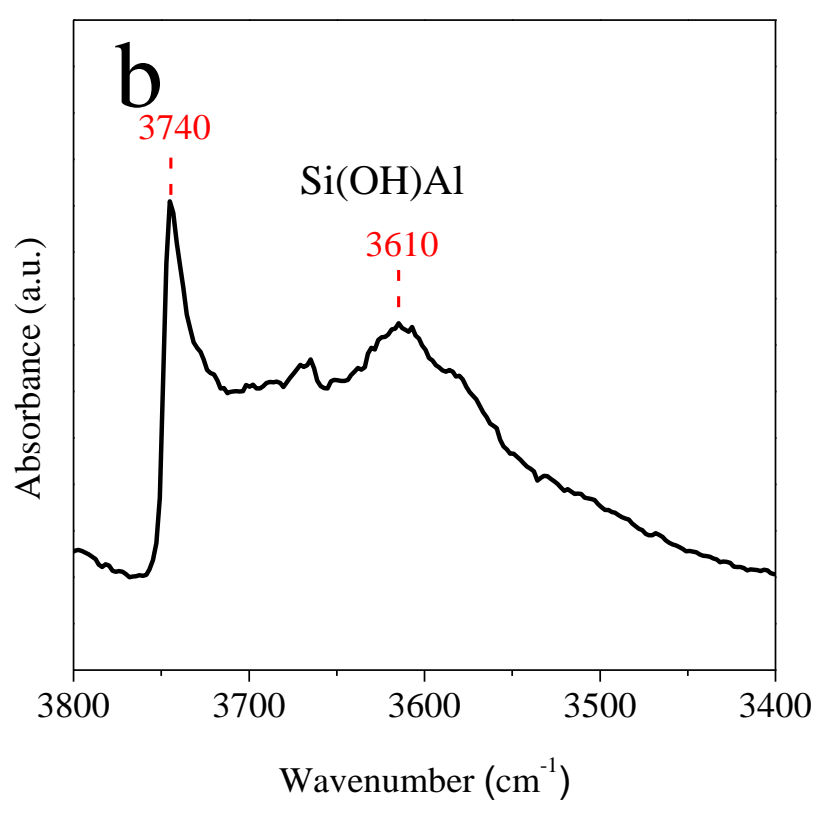

Figure S23. ${ }^{27} \mathrm{Al}$ MAS NMR spectrum (a) and IR spectrum in hydroxyl stretching region (b) of ECNU-27 $(\mathrm{Si} / \mathrm{Al}=28)$.

The tetrahedral coordinated Al species in ECNU-27 was revealed by ${ }^{27} A l M A S N M R$, which contributed to the bridging $\mathrm{Si}(\mathrm{OH})$ Al hydroxyl groups in framework as shown in IR spectrum as $3610 \mathrm{~cm}^{-1}$ band. 

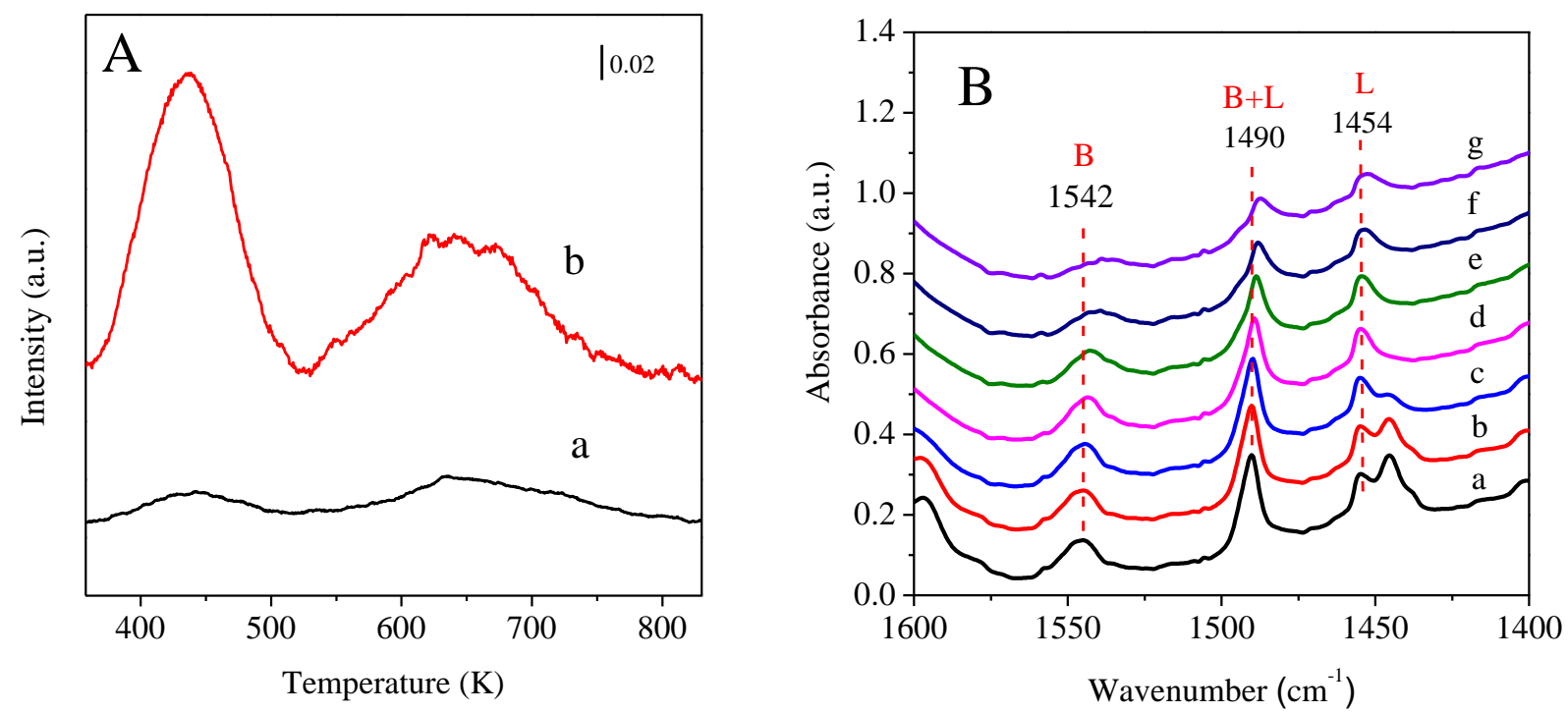

Figure S24. (A) The $\mathrm{NH}_{3}$-TPD profile of NON (a: $\mathrm{Si} / \mathrm{Al}=36$ ) and ECNU-27 (b: Si/Al=28); (B) Pyridine-adsorbed IR spectra of ECNU-27. The samples were evacuated at $773 \mathrm{~K}$ for $1 \mathrm{~h}$. After pyridine adsorption at $298 \mathrm{~K}$ for $30 \mathrm{~min}$, the desorption was performed at $298 \mathrm{~K}$ (a), $373 \mathrm{~K}$ (b), $423 \mathrm{~K}$ (c), $473 \mathrm{~K}$ (d), $523 \mathrm{~K}$ (e), $623 \mathrm{~K}$ (f) and $723 \mathrm{~K}$ (g) for $1 \mathrm{~h}$, respectively.

As shown in Figure S23A, the desorption of ammonia in the temperature range of 373 - $525 \mathrm{~K}$ was attributed to the weak acid sites and that in the range of 525 - $773 \mathrm{~K}$ was attributed to the strong acid sites. The amount of $\mathrm{NH}_{3-}$ accessible acid sites of ECNU-27 (0.26 mmol $\left.\mathrm{g}^{-1}\right)$ was obviously higher than that of NON (0.02 $\left.\mathrm{mmol} \mathrm{g}^{-1}\right)$ with comparable Si/Al ratio, implying the open structure for ECNU-27. The bands at around $1454 \mathrm{~cm}^{-1}$ and $1542 \mathrm{~cm}^{-1}$ in Figure S23B are assigned to pyridine adsorbed on the Lewis acid sites and the Brønsted acid sites, respectively ${ }^{7}$. After elevating the desorption temperature to $723 \mathrm{~K}$, the two bands were still visible, confirming the stable and accessible acid sites in ECNU-27. 


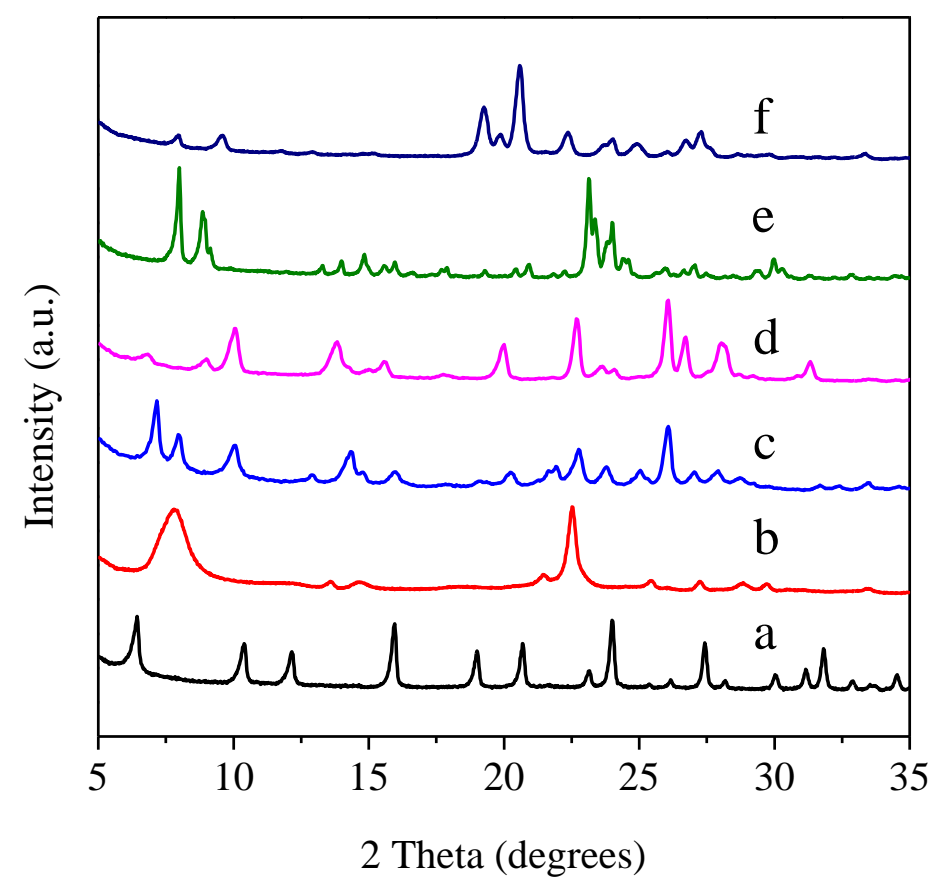

Figure S25. PXRD patterns of post-treatment catalysts with USY (a), Beta (b), MCM-22 (c), MOR (d), ZSM-5 (e) and NON (f) for 1-butene cracking.

The crystallinity of all the zeolite catalysts was well-preserved after dealumination or ammonium cationexchange procedures. 


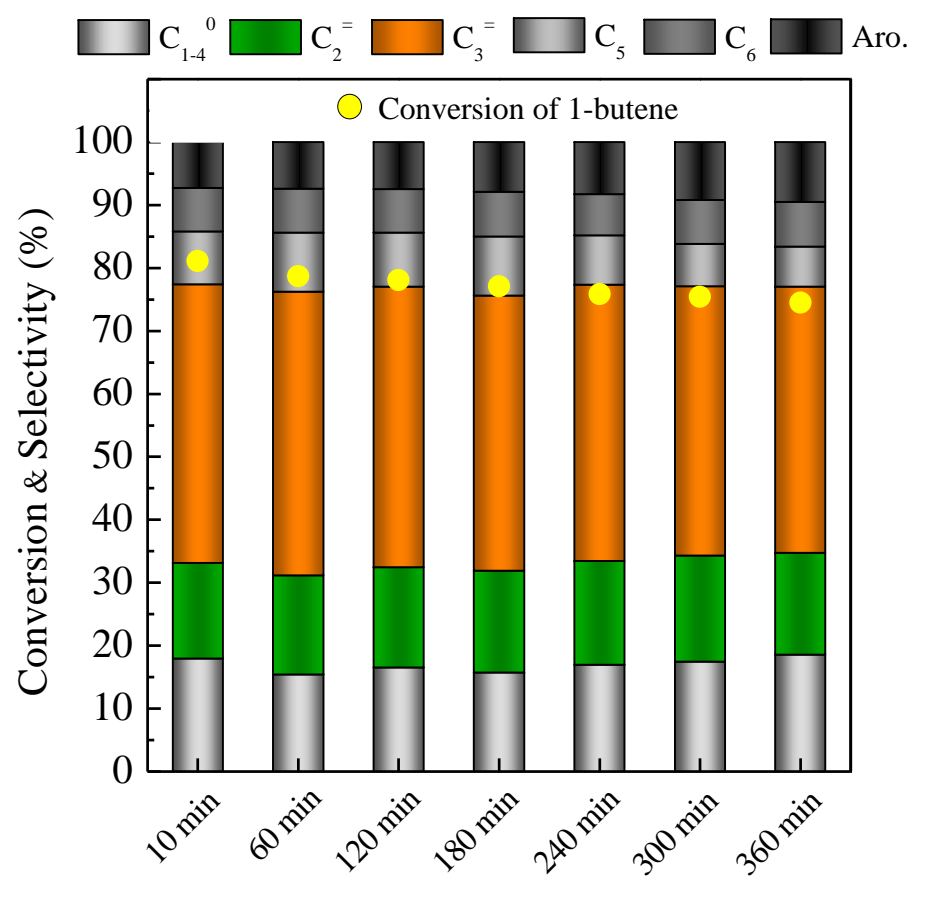

Figure S26. The conversion of 1-butene and the selectivity of products produced from catalytic cracking over ECNU27 ( $\mathrm{Si} / \mathrm{Al}=28$ ). Reaction conditions: catalyst, $0.1 \mathrm{~g}$; WHSV, $3 \mathrm{~h}^{-1}$; temp., $773 \mathrm{~K} ; \mathrm{N}_{2}$ gas flow rate, $30 \mathrm{~mL} \mathrm{~min}{ }^{-1}$.

The conversion of 1-butene over ECNU-27 was slightly decreased with prolonging the reaction time, while the selectivities of ethylene and propylene were barely changed. 


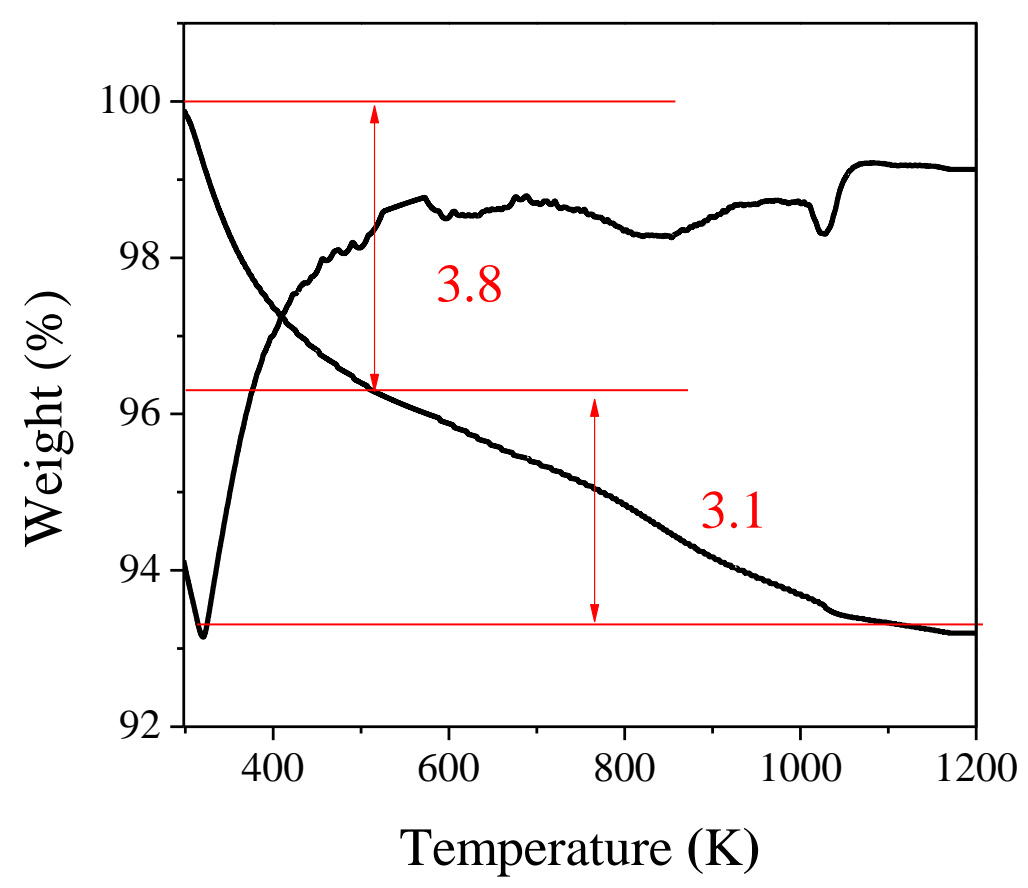

Figure S27. TG-DTG curves of used ECNU-27 ( $\mathrm{Si} / \mathrm{Al}=28)$ for 1-butene cracking reaction.

A considerable weight loss (3.1 wt.\%) in the temperature range of 523-1100 K due to carbon deposition, was observed for the used ECNU-27 in 1-butene cracking reaction after 6 h. The carbon deposition lead to the gradual degradation of 1-butene conversion. 
Table S1. Parametric study of the synthesis conditions of ECNU-27 zeolite

\begin{tabular}{|c|c|c|c|c|c|c|c|c|}
\hline \multirow{2}{*}{ No. } & \multicolumn{4}{|c|}{ Gel composition } & \multirow{2}{*}{$\begin{array}{l}\text { Temp. } \\
(\mathrm{K})\end{array}$} & \multirow{2}{*}{$\begin{array}{l}\text { Time } \\
\text { (days) }\end{array}$} & \multirow{2}{*}{ Product phase } & \multirow{2}{*}{$\begin{array}{l}\text { Product } \\
\mathrm{Si} / \mathrm{Al}^{a}\end{array}$} \\
\hline & $\mathrm{Si} / \mathrm{Al}$ & $\mathrm{Na}_{2} \mathrm{O} / \mathrm{SiO}_{2}$ & $\mathrm{SDA} / \mathrm{Si}$ & $\mathrm{H}_{2} \mathrm{O} / \mathrm{Si}$ & & & & \\
\hline 1 & 10 & 0.1 & 0.1 & 40 & 433 & 7 & MOR & 8.2 \\
\hline 2 & 20 & 0.1 & 0.1 & 40 & 433 & 14 & ECNU-27 & 25.7 \\
\hline 3 & 30 & 0.1 & 0.1 & 40 & 433 & 14 & ECNU-27 & 28.1 \\
\hline 4 & 40 & 0.1 & 0.1 & 40 & 433 & 14 & ECNU-27 & l \\
\hline 5 & 50 & 0.1 & 0.1 & 40 & 433 & 14 & ECNU-27/quartz & I \\
\hline 6 & 60 & 0.1 & 0.1 & 40 & 433 & 14 & quartz & / \\
\hline 7 & 30 & 0.1 & 0.1 & 20 & 433 & 14 & ECNU-27 & 28.5 \\
\hline 8 & 30 & 0.1 & 0.1 & 30 & 433 & 14 & ECNU-27 & 27.8 \\
\hline 9 & 30 & 0.1 & 0.1 & 50 & 433 & 14 & ECNU-27/Amor. ${ }^{b}$ & I \\
\hline 10 & 30 & 0.1 & 0.1 & 60 & 433 & 14 & Amor. & l \\
\hline 11 & 30 & 0.1 & 0.05 & 40 & 433 & 14 & Amor. & I \\
\hline 12 & 30 & 0.15 & 0.05 & 40 & 433 & 7 & MOR & I \\
\hline 13 & 30 & 0.2 & 0.05 & 40 & 433 & 7 & MOR & I \\
\hline 14 & 30 & 0.1 & 0.2 & 40 & 433 & 14 & ECNU-27 & 26.4 \\
\hline 15 & 30 & 0.1 & 0.3 & 40 & 433 & 14 & ECNU-27 & 26.8 \\
\hline 16 & 10 & 0.05 & 0.1 & 40 & 433 & 14 & Amor. & I \\
\hline 17 & 15 & 0.05 & 0.1 & 40 & 433 & 14 & Amor. & I \\
\hline 18 & 20 & 0.05 & 0.1 & 40 & 433 & 14 & Amor. & I \\
\hline 19 & 30 & 0.05 & 0.1 & 14 & 433 & 14 & Amor. & I \\
\hline 20 & 40 & 0.05 & 0.1 & 14 & 433 & 14 & Amor. & I \\
\hline 21 & 50 & 0.05 & 0.1 & 14 & 433 & 14 & Amor. & I \\
\hline 22 & 10 & 0.15 & 0.1 & 40 & 433 & 7 & MOR & I \\
\hline 23 & 15 & 0.15 & 0.1 & 40 & 433 & 7 & MOR & I \\
\hline 24 & 20 & 0.15 & 0.1 & 40 & 433 & 7 & quartz & I \\
\hline 25 & 30 & 0.15 & 0.1 & 14 & 433 & 14 & quartz & I \\
\hline 26 & 40 & 0.15 & 0.1 & 14 & 433 & 14 & quartz & I \\
\hline 27 & 50 & 0.15 & 0.1 & 14 & 433 & 14 & Amor. & I \\
\hline 28 & 30 & 0.1 & 0.1 & 40 & 423 & 14 & Amor. & I \\
\hline 29 & 30 & 0.1 & 0.1 & 40 & 443 & 14 & ECNU-27 & 26.7 \\
\hline
\end{tabular}

${ }^{a}$ Provided by the ICP-AES.

${ }^{b}$ Amorphous phase. 
Table S2. Crystallographic data of NON-related structures ${ }^{a}$

\begin{tabular}{cccccccc}
\hline \multirow{2}{*}{ Name } & \multicolumn{9}{c}{ Unit Cell parameters } & \multirow{2}{*}{$\begin{array}{c}\text { Space } \\
\text { Group }\end{array}$} \\
\cline { 2 - 6 } & $a(\AA)$ & $b(\AA)$ & $c(\AA)$ & $\alpha\left(^{\circ}\right)$ & $\beta\left(^{\circ}\right)$ & $\gamma\left(^{\circ}\right)$ & \\
\hline NON & 22.8620 & 15.6560 & 13.9350 & 90 & 90 & 90 & Fmmm \\
Type A NON & 22.8620 & 23.6840 & 13.9350 & 90 & 90 & 90 & Bmmm \\
Type B NON & 22.8620 & 26.3980 & 13.9350 & 90 & 90 & 90 & Bmmm
\end{tabular}

$\overline{{ }^{a}}$ The hypothetical structure models were built using Material Studio and modified by program DLS$76^{8}$.

(a) Atomic coordinates for NON

\begin{tabular}{cccc} 
Atom. & $\mathrm{x}$ & $\mathrm{y}$ & $\mathrm{z}$ \\
\hline $\mathrm{O} 1$ & 0.3492 & 0.0842 & 0.2495 \\
$\mathrm{O} 2$ & 0.4425 & 0.1420 & 0.3385 \\
$\mathrm{O} 3$ & 0.3737 & 0.2500 & 0.2500 \\
$\mathrm{O} 4$ & 0.3376 & 0.1775 & 0.4060 \\
$\mathrm{O} 5$ & 0.2500 & 0.2500 & 0.0000 \\
$\mathrm{O} 6$ & 0.2628 & 0.4162 & 0.0000 \\
$\mathrm{O} 7$ & 0.5000 & 0.1239 & 0.5000 \\
O8 & 0.5000 & 0.0000 & 0.6279 \\
O9 & 0.3176 & 0.5000 & 0.4048 \\
$\mathrm{O} 10$ & 0.2500 & 0.5000 & 0.2500 \\
$\mathrm{~T} 1$ & 0.3757 & 0.1625 & 0.3103 \\
$\mathrm{~T} 2$ & 0.2969 & 0.3264 & 0.0000 \\
$\mathrm{~T} 3$ & 0.5000 & 0.1018 & 0.6127 \\
$\mathrm{~T} 4$ & 0.3162 & 0.5000 & 0.2892 \\
$\mathrm{~T} 5$ & 0.2778 & 0.5000 & 0.5000 \\
\hline
\end{tabular}




\begin{tabular}{|c|c|c|c|}
\hline Atom. & $\mathrm{x}$ & $\mathrm{y}$ & Z \\
\hline $\mathrm{O} 1$ & 0.34929 & 0.05583 & 0.24913 \\
\hline $\mathrm{O} 2$ & 0.44244 & 0.09419 & 0.33881 \\
\hline $\mathrm{O} 3$ & 0.33738 & 0.11617 & 0.40619 \\
\hline $\mathrm{O} 4$ & 0.35084 & 0.38899 & 0.73490 \\
\hline O5 & 0.44296 & 0.42182 & 0.83472 \\
\hline O6 & 0.33891 & 0.42974 & 0.90580 \\
\hline $\mathrm{O} 7$ & 0.65226 & 0.27745 & 0.75845 \\
\hline O8 & 0.55762 & 0.23646 & 0.83834 \\
\hline O9 & 0.66192 & 0.20979 & 0.90641 \\
\hline $\mathrm{O} 10$ & 0.37314 & 0.16681 & 0.25354 \\
\hline O11 & 0.31772 & 0.32200 & 0.40379 \\
\hline $\mathrm{O} 12$ & 0.62933 & 0.5 & 0.22935 \\
\hline $\mathrm{O} 13$ & 0.24743 & 0.16820 & 0 \\
\hline $\mathrm{O} 14$ & 0.26990 & 0.27872 & 0 \\
\hline O15 & 0.75109 & 0.38968 & 0 \\
\hline O16 & 0.72814 & 0.5 & 0 \\
\hline $\mathrm{O} 17$ & 0.73839 & 0.05594 & 0.5 \\
\hline $\mathrm{O} 18$ & 0.5 & 0.07996 & 0.5 \\
\hline O19 & 0.5 & 0.41524 & 0 \\
\hline $\mathrm{O} 20$ & 0.5 & 0.24401 & 0 \\
\hline $\mathrm{O} 21$ & 0.5 & 0 & 0.63210 \\
\hline $\mathrm{O} 22$ & 0.5 & 0.32969 & 0.12038 \\
\hline $\mathrm{O} 23$ & 0.31776 & 0 & 0.90441 \\
\hline $\mathrm{O} 24$ & 0.25 & 0.33569 & 0.25 \\
\hline $\mathrm{O} 25$ & 0.25 & 0 & 0.75 \\
\hline $\mathrm{T} 1$ & 0.37561 & 0.10762 & 0.31027 \\
\hline $\mathrm{T} 2$ & 0.37595 & 0.43576 & 0.80807 \\
\hline $\mathrm{T} 3$ & 0.62464 & 0.22313 & 0.81106 \\
\hline $\mathrm{T} 4$ & 0.31611 & 0.33142 & 0.28912 \\
\hline T5 & 0.29730 & 0.21613 & 0 \\
\hline T6 & 0.70092 & 0.43723 & 0 \\
\hline $\mathrm{T} 7$ & 0.70367 & 0.11501 & 0.5 \\
\hline $\mathrm{T} 8$ & 0.27916 & 0.32739 & 0.5 \\
\hline $\mathrm{T} 9$ & 0.5 & 0.06696 & 0.61326 \\
\hline $\mathrm{T} 10$ & 0.5 & 0.39742 & 0.11150 \\
\hline $\mathrm{T} 11$ & 0.5 & 0.26199 & 0.11138 \\
\hline T12 & 0.31624 & 0 & 0.78876 \\
\hline $\mathrm{T} 13$ & 0.27824 & 0 & 0 \\
\hline
\end{tabular}


(c) Atomic coordinates for type B NON

\begin{tabular}{|c|c|c|c|}
\hline Atom. & $\mathrm{x}$ & $\mathrm{y}$ & $\mathrm{z}$ \\
\hline $\mathrm{O} 1$ & 0.65097 & 0.94644 & 0.25630 \\
\hline $\mathrm{O} 2$ & 0.55750 & 0.90397 & 0.34133 \\
\hline $\mathrm{O} 3$ & 0.66475 & 0.87882 & 0.40637 \\
\hline $\mathrm{O} 4$ & 0.36042 & 0.74127 & 0.72292 \\
\hline O5 & 0.44243 & 0.78271 & 0.83584 \\
\hline O6 & 0.33456 & 0.77464 & 0.90460 \\
\hline $\mathrm{O} 7$ & 0.66919 & 0.64166 & 0.76951 \\
\hline $\mathrm{O} 8$ & 0.55856 & 0.62459 & 0.83606 \\
\hline O9 & 0.64987 & 0.57048 & 0.90598 \\
\hline $\mathrm{O} 10$ & 0.63594 & 0.84558 & 0.23461 \\
\hline O11 & 0.30059 & 0.67930 & 0.40537 \\
\hline $\mathrm{O} 12$ & 0.5 & 0.70259 & 0.07997 \\
\hline $\mathrm{O} 13$ & 0.25 & 0.71884 & 0.25 \\
\hline $\mathrm{O} 14$ & 0.17065 & 0.5 & 0.90537 \\
\hline $\mathrm{O} 15$ & 0.5 & 0 & 0.63921 \\
\hline O16 & 0.31730 & 0 & 0.90483 \\
\hline O17 & 0.25 & 0 & 0.75 \\
\hline O18 & 0.74462 & 0.83549 & 0 \\
\hline O19 & 0.29724 & 0.65446 & 0 \\
\hline $\mathrm{O} 20$ & 0.76346 & 0.94466 & 0 \\
\hline $\mathrm{O} 21$ & 0.5 & 0.80088 & 0 \\
\hline $\mathrm{O} 22$ & 0.5 & 0.60498 & 0 \\
\hline $\mathrm{O} 23$ & 0 & 0.92476 & 0 \\
\hline $\mathrm{O} 24$ & 0.61020 & 0.55441 & 0.72489 \\
\hline $\mathrm{O} 25$ & 0.25180 & 0.55527 & 0 \\
\hline $\mathrm{O} 26$ & 0.74594 & 0.73327 & 0 \\
\hline $\mathrm{O} 27$ & 0.43148 & 0.5 & 0.58713 \\
\hline $\mathrm{T} 1$ & 0.62502 & 0.89347 & 0.31451 \\
\hline $\mathrm{T} 2$ & 0.37389 & 0.78379 & 0.81031 \\
\hline $\mathrm{T} 3$ & 0.62154 & 0.59811 & 0.81122 \\
\hline $\mathrm{T} 4$ & 0.31016 & 0.69472 & 0.29407 \\
\hline $\mathrm{T} 5$ & 0.5 & 0.93363 & 0.61442 \\
\hline T6 & 0.5 & 0.76923 & 0.10252 \\
\hline $\mathrm{T} 7$ & 0.5 & 0.63597 & 0.10317 \\
\hline $\mathrm{T} 8$ & 0.61097 & 0.5 & 0.65583 \\
\hline $\mathrm{T} 9$ & 0.31602 & 0 & 0.78934 \\
\hline $\mathrm{T} 10$ & 0.31341 & 0.58821 & 0 \\
\hline $\mathrm{T} 11$ & 0.70472 & 0.77956 & 0 \\
\hline $\mathrm{T} 12$ & 0.79430 & 0.88360 & 0 \\
\hline $\mathrm{T} 13$ & 0.76205 & 0.69125 & 0 \\
\hline $\mathrm{T} 14$ & 0.21092 & 0.5 & 0 \\
\hline $\mathrm{T} 15$ & 0.27734 & 0 & 0 \\
\hline
\end{tabular}


Table S3. Chemical composition of organic species in as-made ECNU-27 samples ${ }^{a}$

\begin{tabular}{ccccc}
\hline Si/Al ratio in gel & C (wt.\%) & H (wt.\%) & N (wt.\%) & $\begin{array}{c}\text { C/N molar } \\
\text { ratio }\end{array}$ \\
\hline 20 & 12.30 & 4.42 & 0.95 & 15.1 \\
30 & 11.44 & 4.14 & 0.89 & 15.0 \\
40 & 11.83 & 4.36 & 0.92 & 15.0 \\
\hline
\end{tabular}

${ }^{a}$ Measured by elementary analysis.

The C/N ratios determined by CHN analysis of as-synthesized ECNU-27 zeolites with different Si/Al ratios matched well with the theoretic value of SDA $(C / N=15)$. These results indicated that the structure of SDA molecules was wellpreserved in the crystallization process. 
Table S4. Textural properties of NON and ECNU-27

\begin{tabular}{ccccccc|c} 
Sample & $\mathrm{Si} / \mathrm{Al}^{a}$ & $\begin{array}{c}\mathrm{V}_{\text {total }} \\
\left(\mathrm{cm}^{3} \cdot \mathrm{g}^{-1}\right)\end{array}$ & $\begin{array}{c}\mathrm{V}_{\text {micro }} \\
\left(\mathrm{cm}^{3} \cdot \mathrm{g}^{-1}\right)\end{array}$ & $\begin{array}{c}\mathrm{V}_{\text {meso }} \\
\left(\mathrm{cm}^{3} \cdot \mathrm{g}^{-1}\right)\end{array}$ & $\begin{array}{c}\mathrm{S}_{\mathrm{BET}}{ }^{b} \\
\left(\mathrm{~m}^{2} \mathrm{~g}^{-1}\right)\end{array}$ & $\begin{array}{c}\mathrm{S}_{\text {ext }}{ }^{c} \\
\left(\mathrm{~m}^{2} \cdot \mathrm{g}^{-1}\right)\end{array}$ & $\begin{array}{c}\text { Accessible acid } \\
\text { sites }^{d} \\
\left(\mathrm{mmol} \mathrm{g}^{-1}\right)\end{array}$ \\
\hline NON & 36 & 0.052 & 0 & 0.052 & 12 & 10 & 0.02 \\
ECNU-27 & 28 & 0.35 & 0.08 & 0.27 & 276 & 134 & 0.26 \\
\hline
\end{tabular}

${ }^{a}$ Provided by the ICP analysis.

${ }^{b}$ Determined by BET method.

${ }^{c}$ Calculated by $t$-plot method.

${ }^{\mathrm{d}}$ Determined by $\mathrm{NH}_{3}$-TPD. 
Table S5. The product distribution of the 1-butene cracking reaction over various zeolite catalysts ${ }^{a}$

\begin{tabular}{|c|c|c|c|c|c|c|c|c|c|c|}
\hline \multirow{2}{*}{ Catalyst $^{b}$} & \multirow{2}{*}{$\begin{array}{l}\text { Conv. } \\
(\%)\end{array}$} & \multirow{2}{*}{$\begin{array}{l}\mathrm{D}_{\mathrm{i}}^{c} \\
(\AA)\end{array}$} & \multirow{2}{*}{$\begin{array}{l}\mathrm{D}_{\mathrm{f}^{d}} \\
(\AA)\end{array}$} & \multicolumn{6}{|c|}{ Selectivity (\%) } & \multirow{2}{*}{$\begin{array}{l}\mathrm{P} / \mathrm{E} \\
\text { ratio }^{f}\end{array}$} \\
\hline & & & & $\mathrm{C}_{1-4^{0}}{ }^{0}$ & $\mathrm{C}_{2}=$ & $\mathrm{C}_{3}=$ & $\mathrm{C}_{5}$ & $\mathrm{C}_{6}$ & Aro. ${ }^{e}$ & \\
\hline NON (36) & 15.6 & 6.50 & 2.30 & 42.6 & 3.4 & 14.9 & 12.7 & 18.9 & 7.5 & 4.38 \\
\hline ECNU-27 (28) & 77.4 & 6.54 & 4.35 & 16.9 & 15.8 & 43.7 & 9.9 & 7.4 & 6.3 & 2.77 \\
\hline USY (6.4) & 90.3 & 11.2 & 7.29 & 34.7 & 6.4 & 26.0 & 10.1 & 8.5 & 14.3 & 0.71 \\
\hline Beta (22) & 86.5 & 6.62 & 6.07 & 38.8 & 5.8 & 27.6 & 8.9 & 7.4 & 11.5 & 0.78 \\
\hline MCM-22 (25) & 87.1 & 9.63 & 4.86 & 23.9 & 10.5 & 33.1 & 11.5 & 8.4 & 12.6 & 0.67 \\
\hline MOR (28) & 82.4 & 6.64 & 6.39 & 31.1 & 13.4 & 23.4 & 9.8 & 11.5 & 10.8 & 2.42 \\
\hline ZSM-5 (31) & 85.3 & 6.30 & 4.64 & 22.4 & 18.3 & 34.2 & 6.1 & 4.6 & 14.8 & 1.87 \\
\hline
\end{tabular}

${ }^{a}$ Reaction conditions: catalyst, $0.1 \mathrm{~g}$; WHSV, $3 \mathrm{~h}^{-1}$; Temp., $773 \mathrm{~K}$; time-on-stream, $10 \mathrm{~min}$; $\mathrm{N}_{2}$ gas flow rate, $30 \mathrm{~mL}$ $\min ^{-1}$.

${ }^{b}$ The numbers in parentheses refers to the $\mathrm{Si} / \mathrm{Al}$ ratio.

${ }^{c}$ Maximum included sphere diameter.

${ }^{d}$ Maximum free sphere diameter.

${ }^{e}$ Aro., aromatics.

${ }^{f} \mathrm{P} / \mathrm{E}$, the $\mathrm{C}_{3}=/ \mathrm{C}_{2}=$ ratio. 


\section{References}

(1) Zhao, X. S.; Lu, G. Q.; Whittaker, A. K.; Millar, G. J.; Zhu, H. Y. Comprehensive study of surface chemistry of MCM-41 using 29Si CP/MAS NMR, FTIR, pyridine-TPD, and TGA. J. Phys. Chem. B 1997, 101, 6525-6531.

(2) Kennedy, G. J.; Lawton, S. L.; Rubin, M. K. 29Si MAS NMR Studies of a High Silica Form of the Novel Molecular Sieve: MCM-22. J. Am. Chem. Soc. 1994, 116, 11000-11003.

(3) Long, Y.; Zhong, W.; Shen, X. The synthesis and properties of zeolite CF-3. J. Incl. Phenom. 1986, 4, 121-127.

(4) Król, M.; Mozgawa, W.; Jastrzębski, W.; Barczyk, K. Application of IR spectra in the studies of zeolites from D4R and D6R structural groups. Micropor. Mesopor. Mater. 2012, 156, 181-188.

(5) Na, K.; Jo, C.; Kim, J.; Cho, K.; Jung, J.; Seo, Y.; Messinger, R. J.; Chmelka, B. F.; Ryoo, R.

Directing Zeolite Structures into Hierarchically Nanoporous Architectures. Science 2011, 333, 328.

(6) Lu, K.; Huang, J.; Ren, L.; Li, C.; Guan, Y.; Hu, B.; Xu, H.; Jiang, J.; Ma, Y.; Wu, P. High

Ethylene Selectivity in Methanol-to-Olefin (MTO) Reaction over MOR-Zeolite Nanosheets. Angew.

Chem. Int. Ed. 2020, 59, 6258-6262.

(7) Emeis, C. A. Determination of Integrated Molar Extinction Coefficients for Infrared Absorption Bands of Pyridine Adsorbed on Solid Acid Catalysts. J. Cata. 1993, 141, 347-354.

(8) “DLS-76 Manual”. http://www.xray.cz/ecm-cd/soft/xray/refine/dls/dls76manual.html. 